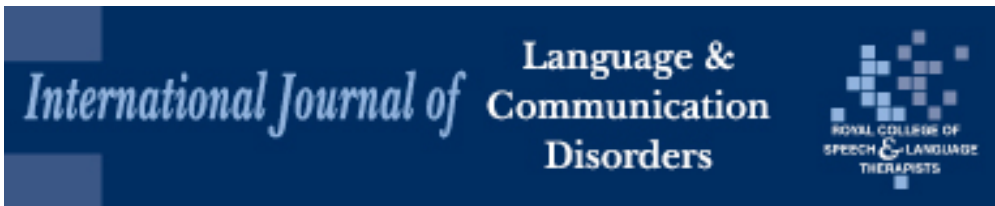

\title{
Assessing speech at three years of age in the cleft palate population: a scoping review of assessment practices
}

\begin{tabular}{|r|l|}
\hline Journal: & International Journal of Language \& Communication Disorders \\
\hline Manuscript ID & TLCD-2019-0074.R1 \\
\hline Wiley - Manuscript type: & Review \\
\hline Keywords: & $\begin{array}{l}\text { cleft palate, cleft lip and palate, speech assessment, speech analysis, } \\
\text { age 3 years, preschool }\end{array}$ \\
\hline \multicolumn{2}{|c|}{ Authors: Beth Fitzpatrick, Jane Coad, Debbie Sell, Tanya Rihtman }
\end{tabular}




\section{Abstract}

2

3 Background: There is no consensus in the UK regarding types of speech samples or

4 parameters of speech which should be assessed at age-3 years in children with cleft palate+/-

5 cleft lip $(C P \pm L)$, despite cleft units routinely assessing speech at this age. Standardisation of

6 assessment practices would facilitate comparisons of outcomes across UK Cleft Units; earlier

7 identification of speech impairments - which could support more timely treatments; more

8 reliable recording of therapy impacts and surgical interventions.

9 Aims: To explore assessment practices used to assess speech in three-year-old children with $10 \mathrm{CP} \pm \mathrm{L}$ including speech parameters, methods of assessment, and nature of speech sample 11 used.

12 Methods: A broad examination of literature was undertaken through the use of a scoping 13 review conducted in accordance with Joanna Briggs Institute guidelines. Search terms were Embase, AMED and PsycINFO).

16 Main Contribution: A combination of approaches (medical, linguistic, developmental and

17 functional) is required to assess $\mathrm{CP} \pm \mathrm{L}$ speech at age-3. A developmental approach is 18 recommended at this age, considering the complexity of speech profiles at age-3, in which 19 typically developing speech processes may occur alongside cleft speech characteristics. A 20 combined measure for both nasal emission and turbulence, and an overall measure for 21 velopharyngeal function for speech, show potential for assessment at this age. Categorical 
1 ordinal scales are frequently used; the use of continuous scales hasyet to be fully explored at

2 age 3 .

3

Although single word assessments, including a subset of words developed for cross-

4 linguistic comparisons, are frequently used, more than one type of speech sample may be

5 needed to validly assess speech at this age. The lack of consensus regarding speech samples

6 highlights a need for further research into the types of speech samples 3-year olds can

7 complete; the impact of incomplete speech samples on outcome measures (particularly

8 relevant at this age when children may be less able to complete a full sample); the impact of

9 different speech samples on the validity of assessments and the reliability of listener 10 judgements.

11 Conclusions: Whilst a medical model and linguistic approaches are often central in 12 assessments of age-3 cleft speech, this review highlights the importance of developmental 13 and functional approaches to assessment. Cross-linguistic single word assessments show 14 potential, and would facilitate the comparison of UK speech outcomes with other countries. 15 Further research should explore the impact of different speech samples and rating scales on 16 assessment valydity and listener eliability. 
1 What this paper adds

2 What is already known on this subject:

3 Although speech is typically assessed at age-3 years in UK cleft units, assessment methods

4 vary. This prevents cross-unit outcome comparisons and is a barrier to measuring the impact

5 of therapy and surgical interventions. There is a need to broadly explore assessment practices

6 to guide the direction of assessments at age-3 years in the UK.

7 What this study adds:

8 This review highlights the importance of a developmental approach to assessment in the 9 assessment of children with $\mathrm{CP} \pm \mathrm{L}$ at age- 3 years. Whilst there is consensus as to the 10 parameters of assessment, there is no such consensus regarding speech samples or methods 11 of assessment.

\section{Clinical implications of the study:}

13 Children at age-3 are at a unique stage of speech development. Assessment procedures and 14 outcomes used with older age groups require adaptation to meet the needs of 3-year-olds, 15 both in terms of the speech sample used and the need to consider developmental and 16 functional outcomes. Whilst further research is needed to provide a foundation for decisions

17 regarding the selection of speech samples, and the impact of different speech samples and

18 methods of assessment on the reliability of listener judgements, cross-linguistic single word assessments show potential and would facilitate international comparisons of outcomes. 
1

\section{Introduction}

2 The speech outcome of individuals with a repaired cleft palate + /-cleft lip $(C P \pm L)$ is a central

3 focus of all cleft teams, as speech outcomes are a primary measure of surgical success

4 (Grunwell and Sell 2001, pp. 68). To this end, a significant focus of cleft research has been on

5 developing speech assessment procedures and outcome measures. Perceptual speech

6 assessment with a basis in phonetic transcription is described as the 'gold standard' for the

7 assessment of speech in individuals with CP $\pm \mathrm{L}$ (Howard 2011, pp. 127). However, there are

8 significant challenges in designing assessment procedures and protocols which allow for

9 speech outcomes to be assessed over a lifespan, as particular speech samples and assessment materials may be more appropriate at certain ages, and assessment objectives may differ across age groups. For example, in children over 5 , and adults speech assessment may focus on the identification of persisting speech difficulties and the impact of anatomical changes (e.g. adenoid atrophy, dentition and occlusion) on speech production (Sell and Pereira 2015). However, for younger children, a focus of assessment may be to examine the impact of the cleft on the process of normal speech sound development (phonology as well as articulation) (Chapman and Willadsen 2011: 25).

Existing protocols such as the Cleft Audit Protocol for Speech-Augmented (CAPS-A) (John et al. 2006, Sell et al. 2009) and the Americleft modification of the CAPS-A, CAPS-A-AM (Chapman et al. 2016) have only been validated and tested for reliability on children aged 5 and above. This is understandable given the original intended use of the CAPS-A in the audit of speech outcomes at age 5 years, an established age for assessing speech outcomes, hence the focus of much attention in the last two decades. Only the Swedish Articulation and Nasality Test (SVANTE) (Lohmander et al. 2005, Lohmander et al. 2009), a valid and reliable 
1 assessment protocol available in Swedish and Norwegian, has been developed for use with

2 children under 5 years with $\mathrm{CP} \pm \mathrm{L}$ (Lohmander et al. 2017a). The Universal Parameters (UPS)

3 (Henningsson et al. 2008), and the Pittsburgh Weighted Values for Speech Symptoms

4 Associated with Velopharyngeal Incompetence (PWSS) (McWilliams \& Philips 1979) are

5 alternative assessment protocols; however, neither has been comprehensively validated

6 (Prathanee et al. 2011, Dudas et al. 2006).

Although UK cleft units routinely carry out speech assessments at age-3, unlike age-5, there is no agreed assessment procedure or outcome measures. Agreed procedures and outcome measures at age-3 would have several benefits. Firstly, valid and reliable outcome measures could be used to identify children at risk of poor speech outcomes at age- 5 and encourage timely referral for intervention. Outcome measures would also facilitate the comparison of outcomes across Cleft Units before 5-years, with the potential to identify variability in outcomes and implement quality improvement initiatives in a similar way to established practices in the UK at age-5 (Cleft Registry and Audit Network [CRANE] 2019). In addition it could permit the collection of comparative longitudinal data, providing an understanding of the impact of therapy and secondary surgery for speech through the comparison of outcomes at age- 3 and 5 .

One well-recognised challenge in the assessment of speech in 3-year-olds is that at this age children go through a period of significant developmental change, refining and acquiring new skills related to their attention, language and speech (Dosman et al. 2012, McLeod and Baker 2017:202). As such, 3-year-old children can be highly variable in how they present in these areas despite being within normal developmental limits. Furthermore, variability in presentation can also result from the known delay in expressive language and 
1 speech (Cavalheiro et al. 2019) and an increased risk of neurodevelopmental disorders

2 (Tillman et al. 2018). This variability presents a challenge when designing assessment

3 protocols, in particular the selection of speech samples and the parameters of speech which

4 can be assessed reliably. Given that children's speech sound systems are in a stage of

5 developmental change (irrespective of the cleft palate) it also raises the question as to the

6 focus of the assessment for children with cleft i.e. whether this focuses purely on those

7 parameters considered core to assessment of cleft speech and/or should include an

8 assessment of speech from a developmental perspective.

9 A broad scope of enquiry was required to examine the methods, parameters of 10 assessment (whether developmental or cleft specific) and speech samples utilised in the 11 assessment of speech in children with $C P \pm L$ at age-3. This was achieved through the use of a 12 scoping review methodology (Khalil et al. 2016). This methodology was selected given that 13 the intention behind the work was to inform the future development of assessment 14 procedures at age-3 in the UK. Rather than answer an effectiveness question (Peters et al. 2015), evaluate study quality, or limit the review to a particular study design (Arksey and O'Malley 2005) or country of origin, the scoping review methodology enabled inclusion of a

17 broad range of resource types, and the broad mapping of current practices, in order to clarify 18 the key concepts, identify gaps in the evidence base and make recommendations for future 19 practice in the UK. In doing so the review identified the extent to which there is consensus in the parameters of assessment, procedures and methods; differences and similarities in assessment at age- 3 years compared to practice at age 5; and the types of speech samples used (Munn et al. 2018). 


\section{Methods}

\section{Ethical Review}

3

4 procedures at Coventry University, study number P68435.

\section{$5 \quad$ Design}

6 To strengthen methodological rigour and to allow replication, the scoping review was

7 undertaken using the Joanna Briggs Institute (JBI) guidance for scoping reviews (Peters et al.

$8 \quad 2015)$ and followed the process outlined below.

\section{$9 \quad \underline{\text { Objective/Aim }}$}

- Explore the parameters of speech typically assessed in 3-year-old children with $\mathrm{CP} \pm \mathrm{L}$, and consider if they are core to the assessment of individuals with $\mathrm{CP} \pm \mathrm{L}$.

- Explore the methods and rating scales used to assess the identified parameters of speech.

- Explore the types of speech samples are utilised in the assessment of 3-yearold children with $\mathrm{CP} \pm \mathrm{L}$. 
1

2

$3 \quad$ Inclusion Criteria

4

5 follows:

$6 \quad$ Types of participants

7

Children age- 3 with $\mathrm{CP} \pm \mathrm{L}$. For inclusion in the review, literature had to specifically

8 include 3-year-olds with details provided as to how speech was assessed at this age (either

9 the parameters of speech, the measurement scales used and/or the speech sample). This

10 resulted in the inclusion of studies also assessing children at other ages i.e. longitudinal

11 studies; however, only data referencing assessment at age-3 was included in the review.

12 Concept
- Discuss how the parameters of speech assessment map onto different theoretical approaches to assessment.

The inclusion criteria were developed with reference to the JBI methodology as 
1 (GOS.SP.ASS' 98) (Sell et al. 1999) marked the start of a new era in speech assessments and

2 outcome measures; this informed the timeframe, with studies reviewed from 1998-2018.

3 Types of Sources

Sources needed to be sufficiently detailed to enable the extraction of sufficient

5 information about assessment procedures, therefore conference abstracts were excluded.

\section{$6 \quad$ Search Strategy}

In accordance with Peters et al. (2015), an initial limited database search was conducted using the EMBASE database to consolidate relevant search terms from the title,

9 abstract and keywords of identified studies and explore controlled vocabulary. Cleft specific search terms as well as general terms such as 'speech assessment' were subsequently 11 included. The final list of search terms is shown in Table 1. Relevant Medical Subject Headings 12 (MeSH [vocabulary used to index publications]) were utilised in the database search. <insert Table 1 here> The electronic databases Medline, Cumulative Index of Nursing \& Allied Health Literature (CINAHL), Embase, AMED and PsycINFO were used. Citation tracking was used to identify additional relevant sources.

\section{Resource Selection}

Figure 1 outlines the study selection processes utilising the flowchart advised in the PRISMA Scoping Review Extension (PRISMA-ScR) flowchart (Tricco et al. 2016). Abstracts were screened for relevance to the objectives of the review and the inclusion criteria, first by title, then by abstract and if necessary, using the full text. With the agreement of the research team 
1 and in an exception to the inclusion criteria, the normative data developed using the SVANTE

2 assessment (Lohmander et al.2017a) was included. Whilst the outcomes presented were not

3 related to children with $\mathrm{CP} \pm \mathrm{L}$, the assessment protocol which was primarily designed to assess

4 structurally based speech difficulties (i.e. cleft palate) and is suitable for children aged 3,

5 provides a detailed account of the assessment procedure and is highly relevant to the

6 objectives of this review. Consideration was also given to a large ongoing research project

7 taking place in the UK, The Cleft Collective Speech and Language Study

8 (https://www.nbt.nhs.uk/bristol-speech-language-therapy-research-unit/bsltru-

9 research/cleft-speech-language-study). As part of the development of the study, a national

10 survey had taken place regarding assessment practices in UK Cleft Centres at age-3. Given the

11 specific relevance of this survey to the aims of this review, with the agreement of the research

12 team, this was included and is referred to asWren 2013).

The final sources included in the review were discussed and confirmed by paired members of the research team. All but one were research papers that appeared in peerreviewed journals. $<$ Insert Figure 1 here $>$

\section{Charting the results}

Studies meeting the inclusion criteria were read in full and charted according to the country of origin, study aim, participant details, methodology and methods, details of the speech assessment and speech sample, the parameters of speech assessed and the rating scales utilised. The parameters of speech assessed across the CAPS-A, CAPS-A-AM, SVANTE, 
1 PWSS and UPS provided a framework for analysis defining those parameters core to the 2 assessment of speech in the $\mathrm{CP} \pm \mathrm{L}$ population.

4 Results

535 sources were reviewed in the scoping review. These are listed in Appendix 1 and 6 detailed in Table 2.

$7 \quad$ <insert Table 2 here>

\section{Demographic Information}

9

The sources originated from 12 countries (see Figure 2). 34\% originated from Sweden, with Scandinavian countries producing $48 \%$ of the sources reviewed.

$<$ Insert Figure 2 here $>$

Apart from one, almost all sources included were primary research and recruited samples of children with CP $\pm \mathrm{L}$. The sub-types are presented in Table 2. It is noteworthy that many of the Scandinavian sources were part of/sub-studies relating to the Scandcleft Trial (Lohmander et al.2017ab, Willadsen et al. 2017), a large multicentre cross-linguistic randomised control trial, evaluating four different surgical protocols. The Scandcleft Trial only recruited participants with Unilateral Cleft Lip and Palate (UCLP), contributing to the high number of sources $(n=13 / 3339.4 \%)$ which only included participants with UCLP. Two sources did not record cleft type (Wren 2013 [reporting assessment practices]; Lohmander et al. 2017a [reporting on non-cleft children]) and were excluded in calculations regarding cleft type. 
2

and are they core to the assessment of individuals with $C P \pm L$ ?

The parameters of speech assessed in each source are charted in Table 3. Each source

4 reported parameters which addressed their specific research aims. As such, not all sources

5 assessed all the parameters identified in this review. Therefore, where percentages are

6 presented, this refers only to those sources which directly assessed the parameter in 7 question. <insert Table 3 here>

\section{Consonant Production}

Almost all sources assessed consonant production. Although phonetic transcription underpinned the assessment of consonant production, a variety of methods were used, 12 shown in Figure 3.

The first principal method used to assess consonant production was to report summary patterns by grouping errors according to their place of articulation, or the broader categories of passive or active characteristics (see Hutters and Brøndsted [1987] for a

17 description of these processes). Such summary patterns can be viewed as a specific measure of cleft speech characteristics (CSCs) and feature in the CAPS-A, CAPS-A-M, UPS, and SVANTE protocols. Despite a strong trend across the studies to report on consonant articulation in summary categories, different summary patterns were used. For example, Safaiean et al. (2017) utilised the UPS summary patterns whilst Persson et al. (2006) identified compensatory articulation using a 3-step process (yes/no scale --> categorising type of 
1 compensatory articulation as retracted oral/pharyngeal/glottal/active nasal fricative/other -2 > recording frequency of error). Chapman et al. (2008) and Hutters et al. (2001) both recorded 3 the frequency with which $\mathrm{CSC}$ /compensatory articulations occurred. The studies highlight 4 that at age-3 there is a consensus on the need to report CSCs, even within the context of a 5 developing sound system, albeit using different summary categories.

6

7 Kwiatkowski 1982). PCC was also used in its adjusted form (PCC-A) (Table 3) in which age8 appropriate speech distortions are classed as correct productions (Shriberg et al. 1997). For example, Klintö et al. (2016, 2015, 2014a,b) utilised PCC-A, with simplifications of phonemes used by more than $10 \%$ of the children scored as correct (Klintö et al. 2016 pp.151). Unlike the summary patterns which specifically focus on CSCs, PCC is a broader measure of all the speech errors including CSCs, developmental and other disordered speech patterns. PCC does not differentiate between articulatory or phonologically based errors. This 'combined approach' is recommended by Lohmander et al. (2017a) as articulation errors (arising from structural or functional abnormalities) may be 'phonologised' (Harding and Grunwell 1995) and become integrated into a child's sound system alongside or replacing developmental phonological patterns. Summary patterns similarly provide phonological information, for example, backing is an example of a common phonological process arising from retracted articulation (Chapman 2003, Willadsen 2012). UK cleft units did not appear to use PCC in the assessment of 3-year-olds (Wren 2013).

Other measures of consonant production included consonant/phoneme inventory which was used in $85.7 \%$ of UK cleft units at age-3 (Wren 2013). This also appeared in several other studies including the SVANTE (Lohmander et al.2017a, Klintö et al. 2014a, Morris \& 
1 Ozanne 2003, Chapman et al. 2008, Chapman 2004, Konst et al. 2003, Hattee et al. 2001). The

2 criteria for inclusion in the inventory varied across the studies. For example (Hattee et al.

3 2001) rated the presence of consonants, Morris \& Ozanne (2003) required phonemes to be

4 heard twice to be included, and Lohmander et al. (2017a) reported correct productions in

5 more than $50 \%$ of the targets.

6

7 (Willadsen et al. 2018, Chacon et al. 2017, Klintö et al. 2016, Klintö et al. 2014a, Klintö et al.

8 2014b, Willadsen 2012, Konst et al. 2003, Morris \& Ozanne 2003 and Hutters et al. 2001). This

9 provides a broader perspective of an individual's phonological development from both a cleft

10 and developmental perspective. In contrast, whilst $78.57 \%$ of UK cleft units assess CSCs at

11 age-3, only 50\% were reported to assess phonology (Wren 2013). Whilst there may be some

overlap between measures of CSCs and phonology, this indicates that a comprehensive phonological assessment may not be considered a priority for assessment in UK cleft units at age-3.

The sources reviewed highlight the importance, at age-3 years, of assessing consonant production both from a cleft and developmental perspective. The methods used in the studies to assess consonant production demonstrate that both PCC and summary patterns can provide information about articulation and phonology.

\section{Resonance}

Both judgements of hypernasality and hyponasality are made in the CAPS-A, CAPS-AAM, UPS, PWSS and SVANTE outcome measures, indicating that these are two parameters core to the assessment of speech in the $C P \pm L$ population. Of those studies assessing 
1 resonance, hypernasality was reported to be specifically assessed in $84.2 \%$ of the studies, as

2 shown in Table 3. Ordinal scales were most frequently used, although scales and descriptors

3 varied. For example, Lohmander et al. (2006) utilised a five-point scale with descriptors,

4 Chapman et al. (2008) used a four-point scale, and Pulkkinen et al. (2001) used a binary scale

5 rating the presence/absence of hypernasality. Whereas hypernasality was sometimes

6 assessed in the absence of hyponasality, hyponasality was always reported alongside

7 hypernasality (see Table 3). Wren (2013) reported that hypernasality and hyponasality are

8 assessed in $92.85 \%$ of UK cleft units at age-3.

9 Although, those studies assessing resonance predominately assessed hypernasality, 10 there was no consensus as to the type or length of scale used.

11 Nasal Airflow Errors

Nasal airflow errors (NAE) is a generic term to describe air escaping inappropriately through the nose during the production of oral pressure consonants (Sweeney 2011: 200). NAE featured in several of the studies reviewed and is therefore also considered core to the assessment of cleft speech at this age. Wren (2013) separated out the parameters of nasal emission and turbulence. In contrast, other studies only reported on audible nasal emission

17 (although this term was possibly used to refer to all NAE i.e. both nasal emission and nasal turbulence) or used a single measure to encapsulate all types of nasal airflow, as per the CAPSA-AM and SVANTE protocols. As with measures of resonance, a variety of scales were used e.g. Konst et al. (2003) measured the percentage of target consonants realised with nasal escape, whereas Lohmander \& Persson (2008) used a five-point scale to measure the frequency with which nasal air leakage occurred. 
1

2

3

4

5

6

7

8

9

10

11

12

13

\section{Velopharyngeal Function}

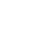

An overall measure of velopharyngeal function based on perceptual speech assessment featured in some studies, as shown in Table 3. This parameter was assessed in addition to those associated with velopharyngeal impairment i.e. hypernasality and NAE. Methods of assessment varied significantly, with some studies utilising a composite score (Swanson et al. 2017; Lohmander et al. 2006; Gunther et al. 1998), whilst others used rating scales (Zanzi et al. 2002; Persson et al. 2006; El Ezzi et al. 2015; Lohmander et al. 2017a; Larsson et al. 2017). Dayashankara et al. (2011) referred to the use of a clinicadliagnosis and Hamming et al. (2009) did not report the methods used. Wren (2013) did not record if an overall measure of velopharyngeal function was used in UK cleft units at age-3.

\section{Intelligibility}

Whitehill et al. (2011) stated that a key objective of all cleft teams is for their patient's speech to be understood and that intelligibility is a measure of how successfully cleft teams have achieved this (Whitehill et al. 2011: 293). Whilst the SVANTE protocol assesses intelligibility, there are well-reported challenges in both defining and measuring intelligibility (see Whitehill [2002]). Despite these challenges, intelligibility was assessed in 11 studies, using methods of orthographic transcription, or categories with descriptors (see Table 3). From a clinical perspective, less than half of the UK cleft units $(42.85 \%)$ reported that intelligibility was assessed at age-3 (Wren 2013).

\section{$\underline{\text { Voice }}$}

Only $20 \%$ of sources reported on the parameter of voice; this is summarised in Table 3. In contrast, voice was reported on in $78.57 \%$ of UK cleft units Wren (2013). One explanation 
1 may be that UK SLTs routinely screen voice (as a parameter of assessment on the CAPS-A, and

2 in clinical assessment using the GOS.SP.ASS) and apply these or similar categories to the

3 assessment of voice at age-3. As such there may be a different culture in the assessment of

4 voice in the UK at age-3 in comparison to other countries.

\section{$5 \quad$ What methods and rating scales are used to assess the parameters of speech identified?}

$6 \quad$ Methods of Assessment

7 Phonetic transcription, as previously stated, underpinned measures of consonant

8 production. This was supplemented in the studies by Chacon et al. (2017), Chapman et al.

9 (2008), Chapman (2004) and Morris \& Ozanne (2003) by computer software to aid the analysis

10 of articulation and phonology. Computer-based analysis was also used by Gugsch et al. (2008)

11 in the evaluation of the voice-specific measures of formants and fundamental frequency.

12 Orthographic transcription using naïve listeners was utilised in studies assessing intelligibility, 13 as shown in Table 3.

14 Categorical rating scales were commonly used (Frey et al. 2018, Chacon et al. 2017, 15 Lohmander et al.2017a, Swanson et al. 2017, El Ezzi et al. 2015, Klintö et al. 2014b, 16 Dayashankara et al. 2011, Hamming et al. 2009, Chapman et al. 2008, Lohmander \& Persson 17 2008, Frederickson et al. 2006, Lohmander et al. 2006, Persson et al. 2006, Chapman 2004, 18 Konst et al. 2003, Zanzi et al. 2002, Gunther et al. 1998, Lohmander-Agerskov 1998, 19 Lohmander-Agerskov et al. 1998), however binary scales also featured (Larsson et al. 2017, 20 Hamming et al. 2009, Pulkkinen et al. 2001). Despite this, there was limited commonality in 21 the categorical scales across the studies with a range of scales, number of scalar points, and 22 descriptors used. As an alternative to categorical scales, Hodge \& Gotzke (2007) utilised a 
1 continuous scale to measure intelligibility, and Chapman et al. (2008) used Direct Magnitude

2 Estimation (DME) to measure articulation proficiency and hypernasality.

$3 \quad$ What types of speech samples are utilised in the assessment of 3-year-old children with $C P \pm L$ ?

4

5 did not provide any information about this. Of the remaining studies, single-word naming was

6 most frequently used, in some instances in combination with other speech samples. A total

7 of eight sources (29\%) used the picture naming test developed as part of the Scandcleft Trial,

8 referred to as the Restricted Word List (as shown in Table 2). This picture naming test has

9 been developed in seven different languages to facilitate cross-linguistic speech comparisons

10 (CLISPI n.d) through the assessment of phonetically similar units of speech across language

11 and context (Lohmander et al. 2009: 348).

Samples of spontaneous speech were also frequently used occurring in $37.14 \%$ of the sources, sometimes in addition to single word naming. Wren (2013) reported that $64.28 \%$ of UK cleft units utilised a spontaneous speech sample in the assessment of 3-year olds with $\mathrm{CP} \pm \mathrm{L}$. Sentence repetition was used by Chacon et al. (2017); participants repeated six sentences taken from the GOS.SP.ASS (Sell et al. 1999). The GOS.SP.ASS was frequently used across UK Cleft units with $85.7 \%$ using this assessment at age-3 (Wren 2013). However, no information is provided as to the type of speech sample used i.e. if it was used in its most common form (using the accompanying sentences) or if short phrases or single words were used. 


\section{Discussion}

2

This scoping review aimed to map assessment practices at age- 3 in the $\mathrm{CP} \pm \mathrm{L}$

3 population. This review found that the evaluation of palatal structure and function through

4 the assessment of resonance, NAE, overall measures of velopharyngeal function and CSCs was

5 a central feature of assessment in many of the sources reviewed, even at this young age.

6 Whilst this approach to assessment is in line with a medical model, it was used alongside a

7 linguistic approach to assessment which was underpinned by phonetic transcription.

8 Although many of the sources had the same assessment objective i.e. to assess palatal

9 function for speech, the assessment methods varied across the studies. The majority of 10 studies reported NAE in combination (e.g. both emission and turbulence ina single measure) 11 including the SVANTE, which is designed to measure speech outcomes at age-3. In contrast, 12 UK cleft units reported nasal emission and turbulence separately, this may be historical and recorded as per the CAPS-A and the GOS.SP.ASS. There is a need for consensus in the UK as to whether the objective at age-3 is to assess the type or overall presence of NAE. To guide this decision making further research is needed to understand the implications of rating nasal emission and turbulence separately or in combination, on listener reliability.

This scoping review indicates that an overall measure of velopharyngeal function was assessed using varying methods. This included the use of validated and unvalidated rating scales and clinical opinions. There is an emphasis on overall measures in the reporting of speech outcomes in the $\mathrm{CP} \pm \mathrm{L}$ population and this has been recommended by ICHOM (2017) for use at older ages. The overall measure VPC-Rate (Lohmander et al. 2009) shows potential for use with this age group; it has been shown to be reliable and efficient (Lohmander et al. 23 2017b) and has featured in a number of studies reporting outcomes associated with the 
1 Scandcleft Trial, and used in a similar form in the SVANTE. In the UK, an overall score for

2 resonance and NAE is used to measure 5-year speech outcomes against National Standards

3 for Speech (Britton et al. 2014) and a velopharyngeal composite score using the CAPS-A has

4 also been validated (Pereira et al. 2013). Further research should compare the reliability of

5 hypernasality, NAE and overall velopharyngeal function at age-3, to support decisions

6 regarding the selection of outcome measures at this age

7 A linguistic approach underpinned by phonetic transcription allowed for both

8 phonetic and phonological analysis of consonant production and the subsequent

9 identification of cleft specific CSCs and calculations of PCC. The frequent reporting of

10 consonant production using cleft summary patterns highlights the importance of this

11 approach during the preschool years. Again, challenges in comparing speech outcomes across

12 the studies arise from the use of different criteria and summary patterns (Sell 2005) and the

13 need for consensus is relevant both at age-3 -years and for other age groups. PCC-A, using a

14 controlled speech sample allows for cross-linguistic comparisons and takes into consideration

15 sound distortions occurring as part of normal development, which is particularly appropriate

16 for assessment at age-3. PCC-A may, therefore, offer a partial solution although it has the

17 disadvantage of not capturing the qualitative nature of speech errors. In addition, to be

18 meaningful, PCC-A needs to be used alongside normative or comparison data (longitudinal

19 data or data to compare groups), which may account for why PCC-A has not been adopted in

20 the UK assessmentsat age-3. Perhaps a solution to the need for normative/comparison data

21 may be to compare PCC-A at ages 3 and 5-years to monitor progress, or to use assessments

22 with available normative data i.e. the DEAP (Dodd et al. 2002), although this has the

23 disadvantage of not being specifically designed to assess cleft speech. 
The assessment of speech from a developmental perspective has not been a core

2 feature in the reporting of cleft speech outcomes (which may account for why the assessment

3 of phonology only featured in $50 \%$ of UK cleft centres [Wren 2013]). However, this scoping

4 review highlights the use of both PCC-A and developmental phonological processes in speech

5 assessments at age-3 demonstrating the use of a combined linguistic and developmental

6 approach to consider delayed, typical and atypical speech production. The importance of a

7 developmental approach is evidenced by studies in this review, as both Chacon et al. (2017)

8 and Hutters et al. (2011) reported that children with $C P \pm L$ present with more developmental

9 phonological processes at age-3 years than their non-cleft peers.

The assessment of intelligibility in the studies included in this review recognises the

need for a functional approach to speech assessment. Whilst not a cleft specific outcome measure, a functional approach to assessment at age- 3 is important given that many children start attending pre-school education in the UK at this age and thus interact with a wider social group. Most studies in the review used ordinal scales to assess intelligibility despite evidence questioning their validity to measure this parameter (Whitehill et al. 2011). In the context of the International Classification of Functioning, Disability and Health: Children and Youth Version (ICF-CY; World Health Organization [WHO], 2007) McLeod et al. (2012: 649) report that intelligibility is influenced by both production factors (Body Functions) and contextual factors (Environmental Factors). Safaiean et al. (2018), Willadsen \& Poulsen (2012) and Hodge and Gotzke (2007) used orthographic transcription by naïve listeners. This method addresses concerns regarding contextual factors and the validity of expert (cleft SLT) listeners rating intelligibility but would be impractical to employ in clinical practice. Indeed, The Intelligibility in Context Scale (ICS) (McLeod at al. 2012), which uses parent ratings of intelligibility, shows 
1 potential for use with the cleft population. The ICS is validated and recommended by ICHO

2 (2017) for use at age 5 and 12 years but has yet to be validated for use at age-3; the challenges

3 and complexity of measuring intelligibility at thisage persist.

4

5

6

7

8

9

10

11

12

In addition to intelligibility, the reliability and validity of using ordinal/categorical scales to measure resonance and NAE has been challenged by growing evidence to suggest that ratio or category-ratio scales may be more valid and reliable measures (Yamashita et al. 2018, Baylis et al. 2015). However, in the studies in this review, only Hodge \& Gotzke (2007) and Chapman et al. (2008) utilised non-categorical scales, using a continuous scale and DME respectively, with good levels of reliability reported in both studies. The impact of different rating scales on the validity and reliability of listener judgements has therefore yet to be fully explored in 3-year-old children with $\mathrm{CP} \pm \mathrm{L}$ and further research is required to determine if findings at this age mirror that of other age groups.

Three types of speech samples were used in the studies: single word production, spontaneous speech samples, and more infrequently, sentence repetition. The variety of assessments used to assess single words is striking and well exemplified by Wren (2013) which indicates there is no preferred single word assessment to evaluate speech at age- 3 in the UK. The use of supplementary assessment materials or unnamed picture naming assessments suggests existing assessments may not be wholly adequate for the comprehensive assessment of speech at age-3 in the $\mathrm{CP} \pm \mathrm{L}$ population. The Restricted Word List (Lohmander et al 2009), developed for cross-linguistic comparisons, would facilitate multi-centre research and comparisons of outcomes internationally. However, given its design to allow crosslinguistic comparisons it does not assess the full range of oral pressure consonants in English and there is a need to expand upon this assessment to assess speech more comprehensively 
1 (as per the SVANTE). Nonetheless, this review highlights its potential use in speech

2 assessments at age-3.

3

4

5

6

7 single word naming samples enhance listener reliability in judgements of consonant

8 production (Klintö et al. 2011). However, evidence that there may be variability in 'speech

9 performance between single words and conversational speech' (Sweeney 2011: 206)

10 indicates that this sample may not be sufficient in isolation, particularly when measuring the

11 core parameters of hypernasality, NAE and consonant production. Although $37.14 \%$ of the

12 studies used a spontaneous speech sample, Klintö et al. (2014b), Persson et al. (2006), and

13 Lohmander and Persson (2008) favoured single words to assess resonance and NAE. Klintö et al (2014b) used only single words reporting that a 'representative and standardised speech sample with connected speech' (Klintö et al. 2014b pp.277) could not be achieved, thus highlighting the challenges of spontaneous speech samples at this age. An alternative is sentence or phrase repetition. Wren (2013) found that $85.7 \%$ of UK cleft units utilised the GOS.SP.ASS and the accompanying speech sample (Sell et al. 1999) in addition to single word assessments. The familiarity UK Cleft SLTs have with the GOS.SP.ASS may help them to support 3-years olds in completing the GOS.SP.ASS sentences, sometimes as short phrases, and may facilitate reliable listener judgements. The SVANTE also includes both single word and sentence level speech samples. 
The parameters of speech identified in the study are those established as core to the

2 assessment of cleft speech and do not constitute novel information. The number of sources

$3(n=8 / 3522.9 \%)$ included in this review which report on outcomes associated with the

4 Scandcleft Trial is a testament to the success of this research group in generating new

5 knowledge. However, it is important to recognise the impact this has on the overall results of

6 this scoping review, introducing an element of bias into the results given that the same

7 assessment principles and processes were used across this subset of studies. The inclusion of

8 sources in languages other than English would have provided a more diverse overview of

9 assessment practices at age-3 in other parts of the world and could potentially have informed

10 UK practice.

\section{Conclusion}

Whilst there are core parameters fundamental to the assessment of cleft speech, this scoping review also highlights the unique assessment requirements of 3-year-old children, particularly with reference to the selection of the speech sample and the importance of using a developmental approach to assessment. The need to assess functional outcomes at this age i.e. intelligibility, in addition to cleft specific outcomes, i.e. resonance and NAE, is highlighted. Unlike age-5, speech outcomes at age- 3 in the $C P \pm L$ population have not been a central focus in the UK or internationally; this is perhaps reflected in the variety of assessment methods noted in this review. However, more recent studies relating to the Scandcleft study highlight the potential of the Restricted Word List (Lohmander et al. 2009) for use in assessments at age-3, particularly as this allows for cross-linguistic comparisons. This scoping review highlights the need for a consolidated approach to assessing $C P \pm L$ speech at age-3, 
21 however, further research is needed to provide a foundation for assessments at this 3

2 important age in order to develop assessment protocols. This should consider the extent to 4

3 which 3-year-oldchildren with $\mathrm{CP} \pm \mathrm{L}$ can complete different speech samples and the impact 10

4 this has on the parameters of speech which can be assessed and the validity and reliability of

5 listener judgements of those parameters using different measures. 
Table 1. Search terms

\begin{tabular}{|c|c|c|}
\hline \multicolumn{2}{|c|}{ Participant Type } & \multirow[t]{2}{*}{ Concept } \\
\hline Age & Diagnosis & \\
\hline $\begin{array}{l}\text { preschool } \\
\text { toddler } \\
\text { kindergarten } \\
\text { nursery } \\
3 \text { years old } \\
\text { aged } 3 \text { years } \\
3 \text { years of age }\end{array}$ & $\begin{array}{l}\text { cleft palate } \\
\text { cleft lip and palate }\end{array}$ & $\begin{array}{l}\text { articulation } \\
\text { cleft speech characteristics } \\
\text { cleft type characteristics } \\
\text { compensatory articulation } \\
\text { velopharyngeal dysfunction } \\
\text { (VPD) } \\
\text { velopharyngeal insufficiency } \\
\text { (VPI) } \\
\text { voice quality/dysphonia } \\
\text { speech articulation } \\
\text { speech analysis } \\
\text { speech assessment } \\
\text { speech and language } \\
\text { assessment }\end{array}$ \\
\hline
\end{tabular}


Table 2. Articles included in the review recorded by author and date, country of origin, methods and methodology, and speech assessment

\begin{tabular}{|c|c|c|c|c|c|}
\hline Author \& Date & $\begin{array}{l}\text { Country of } \\
\text { Origin }\end{array}$ & Age of Participants & $\begin{array}{l}\text { Cleft } \\
\text { Type* }\end{array}$ & Methodology and Methods & Speech Assessment \\
\hline $\begin{array}{l}\text { Frey et al. } \\
\text { (2018) }\end{array}$ & USA & $15-36 \mathrm{mo}$ & CPL & $\begin{array}{l}\text { CPL recruited from a larger randomised } \\
\text { experimental group design }\end{array}$ & Spontaneous speech sample \\
\hline $\begin{array}{l}\text { Willadsen et al. } \\
(2018)\end{array}$ & Denmark & $36 \mathrm{mo}$, mean $3.0 \mathrm{y}$, (Range $2.93-3.23 \mathrm{y})$ & $\begin{array}{l}\text { UCLP } \\
\text { NCCG }\end{array}$ & $\begin{array}{l}\text { Randomised Control Trial } \\
\text { (randomised by age at hard palate repair) }\end{array}$ & $\begin{array}{l}\text { Single word naming using the naming test developed in the Scandcleft study } \\
\text { (Lohmander et al. 2009) }\end{array}$ \\
\hline $\begin{array}{l}\text { Chacon et al. } \\
\text { (2017) }\end{array}$ & Australia & $\begin{array}{l}3 \text { y-olds: } 2 ; 10-3 ; 11 \text { y } \\
5 \text { y-olds: } 4 ; 10-5 ; 09 \text { y }\end{array}$ & $\begin{array}{l}\text { CPO } \\
\text { UCLP } \\
\text { BCLP }\end{array}$ & Cross-sectional observation study & $\begin{array}{l}\text { GOS.SP.ASS } \times 6 \text { sentences } \\
\text { DEAP Articulation subtest (Dodd et al. 2002), single words } \\
\text { Informal list of } 15 \text { monosyllabic and } 10 \text { polysylabbic words }\end{array}$ \\
\hline $\begin{array}{l}\text { Larsson et al. } \\
\text { (2017) }\end{array}$ & Sweden & $\begin{array}{l}\text { Adopted group: } 38 \text { mo (Range } 35-43 \\
\text { mo); Control group (also cleft) } 37 \text { mo } \\
\text { (Range } 34-42 \mathrm{mo} \text { ) }\end{array}$ & UCLP & Cohort Study & $\begin{array}{l}\text { SVANTE (Lohmander et al. 2005, 2015). Single word naming and spontaneous speech } \\
\text { sample. }\end{array}$ \\
\hline $\begin{array}{l}\text { Lohmander et } \\
\text { al. (2017a) }\end{array}$ & Sweden & $\begin{array}{l}\text { Normative Data gained at } \\
3,5,7,10,16,19 \text { y } \\
3 \text { y-olds: Mean age } 2 ; 11 \\
\text { (Range } 2 \text { y } 8 \text { mo-3 y } 3 \text { mo) }\end{array}$ & $\begin{array}{l}\text { NCCG- } \\
\text { Normative } \\
\text { Data }\end{array}$ & Normative Referencing & $\begin{array}{l}\text { SVANTE (Lohmander et al. 2005, 2015). Single word naming, sentence repetition, } \\
\text { spontaneous speech sample. }\end{array}$ \\
\hline $\begin{array}{l}\text { Raud Westberg } \\
\text { et al. (2017) }\end{array}$ & Sweden & $\begin{array}{l}\text { Longitudinal assessment at age } 1,1 \text { y } 6 \\
\mathrm{~m} \text { and } 3 \mathrm{y}\end{array}$ & UCLP & Randomised Control Trial & $\begin{array}{l}\text { Single word naming using the naming test developed in the Scandcleft study } \\
\text { (Lohmander et al. 2009) }\end{array}$ \\
\hline $\begin{array}{l}\text { Swanson et al. } \\
\text { (2017) }\end{array}$ & USA & Initial assessment at age $3 \mathrm{y}$ & SMCP & Retrospective review & $\begin{array}{l}\text { Pittsburgh Weighted Speech Scoring (McWilliams \& Philips 1979) (no information } \\
\text { provide as to what the speech sample was) }\end{array}$ \\
\hline $\begin{array}{l}\text { Klintö et al. } \\
\text { (2016) }\end{array}$ & Sweden & $\begin{array}{l}\text { Mean }=36 \mathrm{mo} \\
\text { (Range 35-38 mo) }\end{array}$ & $\begin{array}{l}\text { UCLP } \\
\text { NCCG }\end{array}$ & $\begin{array}{l}\text { Randomised Control Trial (some participants) } \\
\text { Prospective longitudinal }\end{array}$ & $\begin{array}{l}\text { Single word naming using the naming test developed in the Scandcleft study } \\
\text { (Lohmander et al. 2009) }\end{array}$ \\
\hline $\begin{array}{l}\text { El Ezzi et al. } \\
\text { (2015) }\end{array}$ & Switzerland & 3 y (no specific age range) & $\begin{array}{l}\text { UCLP } \\
\text { CPO }\end{array}$ & Retrospective cohort study & Not stated \\
\hline $\begin{array}{l}\text { Klintö et al. } \\
(2015)^{* *} \text { same } \\
\text { procedure as } \\
\text { Klintö 2014a) }\end{array}$ & Sweden & $\begin{array}{l}\text { Median: } 36 \mathrm{mo} \\
\text { (Range } 35.5-37 \mathrm{mo} \text { ) }\end{array}$ & $\begin{array}{l}\text { UCLP } \\
\text { NCCG }\end{array}$ & $\begin{array}{l}\text { Prospective comparative study } 5 y \text {, and } \\
\text { retrospective comparative study at } 3 y\end{array}$ & $\begin{array}{l}\text { Single word naming using the naming test developed in the Scandcleft study } \\
\text { (Lohmander et al. 2009) }\end{array}$ \\
\hline $\begin{array}{l}\text { Klintö et al. } \\
\text { (2014a) }\end{array}$ & Sweden & $\begin{array}{l}\text { Median: } 36 \text { mo } \\
\text { (Range 35.5-37 months) }\end{array}$ & $\begin{array}{l}\text { UCLP } \\
\text { NCCG }\end{array}$ & $\begin{array}{l}\text { Randomised Control Trial } \\
\text { (randomised by age at hard palate repair) }\end{array}$ & $\begin{array}{l}\text { Single word naming using the naming test developed in the Scandcleft study } \\
\text { (Lohmander et al. 2009) } \\
\text { Sample of spontaneous speech }\end{array}$ \\
\hline $\begin{array}{l}\text { Klintö et al. } \\
\text { (2014b) }\end{array}$ & Sweden & $\begin{array}{l}\text { Group 1: mean age } 36 \text { mo } \\
\text { Group 2: mean age } 35-39 \text { mo }\end{array}$ & UCLP & Prospective comparison study & $\begin{array}{l}\text { Single word naming using the naming test developed in the Scandcleft study } \\
\text { (Lohmander et al. 2009) } \\
\text { Sample of spontaneous speech }\end{array}$ \\
\hline
\end{tabular}




\begin{tabular}{|c|c|c|c|c|c|}
\hline $\begin{array}{l}\text { Wren } \\
(2013)\end{array}$ & UK & $\begin{array}{l}\text { N/A Report on assessment practises of } \\
\text { speech and language therapists }\end{array}$ & N/A & Survey of 14 UK Cleft Units (\% of cleft units) & $\begin{array}{l}\text { South Tyneside Assessment of Phonology (STAP) (Armstrong 1992): } 21.42 \% \\
\text { Diagnostic Evaluation of Articulation \& Phonology (Dodd et al. 2002): } 28.57 \% \\
\text { PACS TOYS (Harding \& Grunwell 1995): } 28.57 \% \\
\text { Phonological Screening Assessment (PSA) (Stevens \& Isles 2001): 14.28\% } \\
\text { Hart Screen Speech Assessment: 14.28\% } \\
\text { CLEAR Phonology Screening Assessment (CLEAR Resources 2006): } 28.57 \% \\
\text { Great Ormond Street Speech Assessment (GOS.SP.ASS) (Sell et al. 1999): } 85.71 \% \\
\text { Renfrew Action Picture Test (Renfrew 2011): } 14.28 \% \\
\text { Preschool Language Scale Version 3 (PLS-3) (Boucher and Lewis 1997): } 21.42 \% \\
\text { Spontaneous Speech: } 64.28 \%\end{array}$ \\
\hline $\begin{array}{l}\text { Willadsen \& } \\
\text { Poulsen (2012) }\end{array}$ & Denmark & $36 \mathrm{mo}$ & $\begin{array}{l}\text { UCLP } \\
\text { NCCG }\end{array}$ & Cross-sectional study & $\begin{array}{l}\text { Single word naming using the naming test developed in the Scandcleft study } \\
\text { (Lohmander et al. 2009) }\end{array}$ \\
\hline $\begin{array}{l}\text { Dayashankara } \\
\text { et al. (2011) }\end{array}$ & India & $18-36 \mathrm{mo}$ & $\begin{array}{l}\text { UCLP } \\
\text { BCLP } \\
\text { CPO }\end{array}$ & Prospective cohort study & Not stated \\
\hline $\begin{array}{l}\text { Hamming et al. } \\
\text { (2009) }\end{array}$ & USA & Younger age group: $3-4$ y (up to 4.11 ) & $\begin{array}{l}\text { UCLP } \\
\text { BCLP } \\
\text { CPO } \\
\text { SMCP }\end{array}$ & Retrospective longitudinal & Not stated \\
\hline $\begin{array}{l}\text { Chapman et al. } \\
(2008)\end{array}$ & USA & $33-42$ mo. Median = $39 \mathrm{mo}$ & CPL & Prospective longitudinal & $\begin{array}{l}\text { Goldman-Fristoe Test of Articulation (Goldman \& Fristoe 1986), single word naming, } \\
\text { spontaneous speech sample }\end{array}$ \\
\hline $\begin{array}{l}\text { Gugsch et al. } \\
\text { (2008) }\end{array}$ & Germany & $\begin{array}{l}\text { Mean age at baseline: } 3 \text { y11mo (Range } \\
3.7-4.7)\end{array}$ & $\begin{array}{l}\text { UCLP } \\
\text { BCLP } \\
\text { CPO }\end{array}$ & Longitudinal prospective & Voice recordings in standardised form \\
\hline $\begin{array}{l}\text { Lohmander \& } \\
\text { Persson (2008) }\end{array}$ & Sweden & $\begin{array}{l}\text { Longitudinal speech assessments at } 18 \\
\text { mo, } 3,5 \text {, and } 7 y\end{array}$ & $\begin{array}{l}\text { UCLP } \\
\text { NCCG }\end{array}$ & Prospective Longitudinal study & Single word picture naming test \\
\hline $\begin{array}{l}\text { Hodge \& } \\
\text { Gotzke (2007) }\end{array}$ & Canada & $\begin{array}{l}\text { Age range: } 3 \text { y } 5 \mathrm{mo}-6 \text { y } 7 \mathrm{mo} \\
\text { Mean } 4 \text { y } 6 \mathrm{mo}\end{array}$ & $\begin{array}{l}\text { UCLP } \\
\text { BCLP } \\
\text { CPO }\end{array}$ & Prospective between groups design & $\begin{array}{l}\text { Single word repetition } \\
\text { Spontaneous speech sample }\end{array}$ \\
\hline $\begin{array}{l}\text { Frederickson et } \\
\text { al.(2006) }\end{array}$ & USA & Age range: 2 y $9 \mathrm{mo}-3$ y $8 \mathrm{mo}$ & $\begin{array}{l}\text { UCLP } \\
\text { NCCG }\end{array}$ & Prospective cross-sectional study & Goldman Fristoe Test of Articulation (Goldman \& Fristoe 1986), single word naming \\
\hline $\begin{array}{l}\text { Lohmander et } \\
\text { al. (2006) }\end{array}$ & Sweden & $\begin{array}{l}\text { Longitudinal speech assessments at } 3 \text {, } \\
5,7,10 \text { y }\end{array}$ & UCLP & $\begin{array}{l}\text { Prospective longitudinal study (3-year results } \\
\text { retrospectively collected) }\end{array}$ & Assessment not stated at age 3 , data collected from records \\
\hline $\begin{array}{l}\text { Persson et al. } \\
(2006)\end{array}$ & Sweden & $\begin{array}{l}\text { Longitudinal speech assessments at } 3 \text {, } \\
\text { 5, 7, } 10 \text { y } \\
\text { Age } 3: \text { Mean age: } 3 \text { y } 0 \text { mo } \\
\text { Range } 3 \text { y } 0 \mathrm{mo}-3 \text { y } 3 \mathrm{mo}\end{array}$ & $\begin{array}{l}\text { CPO } \\
\text { NCCG }\end{array}$ & Longitudinal study (3-7yrs) & $\begin{array}{l}\text { Single word naming } \\
\text { Spontaneous speech if unable to complete naming }\end{array}$ \\
\hline $\begin{array}{l}\text { Chapman } \\
\text { (2004) }\end{array}$ & USA & $\begin{array}{l}\text { Longitudinal assessment, final } \\
\text { assessment at } 39 \mathrm{mo}\end{array}$ & $\begin{array}{l}\text { UCLP } \\
\text { BCLP }\end{array}$ & Multi-site longitudinal study & Spontaneous speech sample \\
\hline
\end{tabular}




\begin{tabular}{|c|c|c|c|c|c|}
\hline $\begin{array}{l}\text { Konst et al. } \\
\text { (2003) }\end{array}$ & $\begin{array}{l}\text { The } \\
\text { Netherlands }\end{array}$ & $\begin{array}{l}\text { Longitudinal follow up at age } 2,2.5 \\
\text { and } 3 \mathrm{y}\end{array}$ & UCLP & Randomised Control Trial & Spontaneous speech sample \\
\hline $\begin{array}{l}\text { Morris \& } \\
\text { Ozanne (2003) }\end{array}$ & Australia & Assessment at age $2 \mathrm{y}$ and $3 \mathrm{y}$ & $\begin{array}{l}\text { UCLP } \\
\text { BCLP } \\
\text { CPO }\end{array}$ & Comparative groups- longitudinal & $\begin{array}{l}\text { Spontaneous speech sample. } \\
\text { Goldman Fristoe Test of Articulation (Goldman \& Fristoe 1986), single word naming }\end{array}$ \\
\hline $\begin{array}{l}\text { Hattee et al. } \\
\text { (2001) }\end{array}$ & UK & $\begin{array}{l}\text { Longitudinal assessment at } 9 \mathrm{mo}, 18 \\
\text { mo and } 3 \mathrm{y}\end{array}$ & $\begin{array}{l}\text { UCLP } \\
\text { CPO }\end{array}$ & Longitudinal study & South Tyneside Assessment of Phonology (STAP) (Armstrong \& Ainsley 1988) \\
\hline $\begin{array}{l}\text { Hutters et al. } \\
\text { (2001) }\end{array}$ & Denmark & $\begin{array}{l}\text { Mean: } 3 \text { y } 1 \mathrm{mo} \\
\text { Range } 2 \text { y } 11 \mathrm{mo}-3 \text { y } 3 \mathrm{mo}\end{array}$ & $\begin{array}{l}\text { UCLP } \\
\text { BCLP }\end{array}$ & Prospective cross-sectional study & Picture naming \\
\hline $\begin{array}{l}\text { Pulkkinen et al. } \\
\text { (2001) }\end{array}$ & Finland & $\begin{array}{l}\text { Longitudinal assessment at } 3,6 \text {, and } 8 \\
y\end{array}$ & $\begin{array}{l}\text { UCLP } \\
\text { CPO }\end{array}$ & Longitudinal & Not stated \\
\hline $\begin{array}{l}\text { Gunther et al. } \\
\text { (1998) }\end{array}$ & USA & Assessment at age $3 \mathrm{y}$ & CPL & Retrospective review & $\begin{array}{l}\text { Pittsburgh Weighted Speech Scale (McWilliams \& Philips 1979) - no information on type } \\
\text { of speech sample }\end{array}$ \\
\hline $\begin{array}{l}\text { Lohmander- } \\
\text { Agerskov } \\
\text { (1998) }\end{array}$ & Sweden & $\begin{array}{l}\text { Longitudinal assessment at } 9 \mathrm{mo}, 18 \\
\text { mo, and } 3,5,7,10,16 \text { and } 19 \mathrm{y}\end{array}$ & $\begin{array}{l}\text { UCLP } \\
\text { BCLP }\end{array}$ & $\begin{array}{l}\text { Results combined from: } \\
\text { Longitudinal study- retrospective and } \\
\text { Cross-sectional study }\end{array}$ & Picture naming \\
\hline $\begin{array}{l}\text { Lohmander- } \\
\text { Agerskov et al. } \\
\text { (1998) }\end{array}$ & Sweden & Assessment at 3 and $5 \mathrm{y}$ & $\begin{array}{l}\text { UCLP } \\
\text { BCLP } \\
\text { CPO }\end{array}$ & Longitudinal study & Picture naming \\
\hline
\end{tabular}

* UCLP= Unilateral Cleft Lip and Palate; BCLP= Bilateral Cleft Lip and Palate; CPO= Cleft Palate Only; SMCP= Submucus cleft palate; CPL= Cleft Palate +/- Cleft Lip (used when specific type of cleft is not stated); NCCG= Non-Cleft Control Group

Additional References for Assessments:

ARMSTRONG, S. and AINLEY, M., 1992, South Tyneside assessment of phonology. Stass Publications.

BOUCHER, J. and LEWIS, V., 1997. Preschool language scale-3 (UK). London: The Psychological Corporation.

CLEAR RESOURCES., 2006, CLEAR Phonology Screening Assessment (Spilsby: Clear Resources).

GOLDMAN, R. and FRISTOE, M., 1986. Goldman Fristoe test of articulation. American Guidance Service.

GRUNWELL, P., and HARDING, A., 1995, PACS TOYS. Windsor, UK: NFER-Nelson.

HEYDARI, S., TORABI NEZHAD, F., AGHA RASOULI, Z., and HOSEYNI, F., 2011, Development of speech intelligibility measurement test for 3 to 5 years old normal children. Bimonthly Audiology-Tehran University of Medical Sciences, 20(1), 47-53.

STEVENS, N. and ISLES, D., 2011, Phonological Screening Assessment (PSA) (London: Taylor and Francis)

RENFREW, C.E., 2011. Action picture test. Speechmark. 
Table 3. Summary of the parameters of speech assessed. Articles which utilised Percentage Consonants Correct categorised as assessing both articulation and phonology.

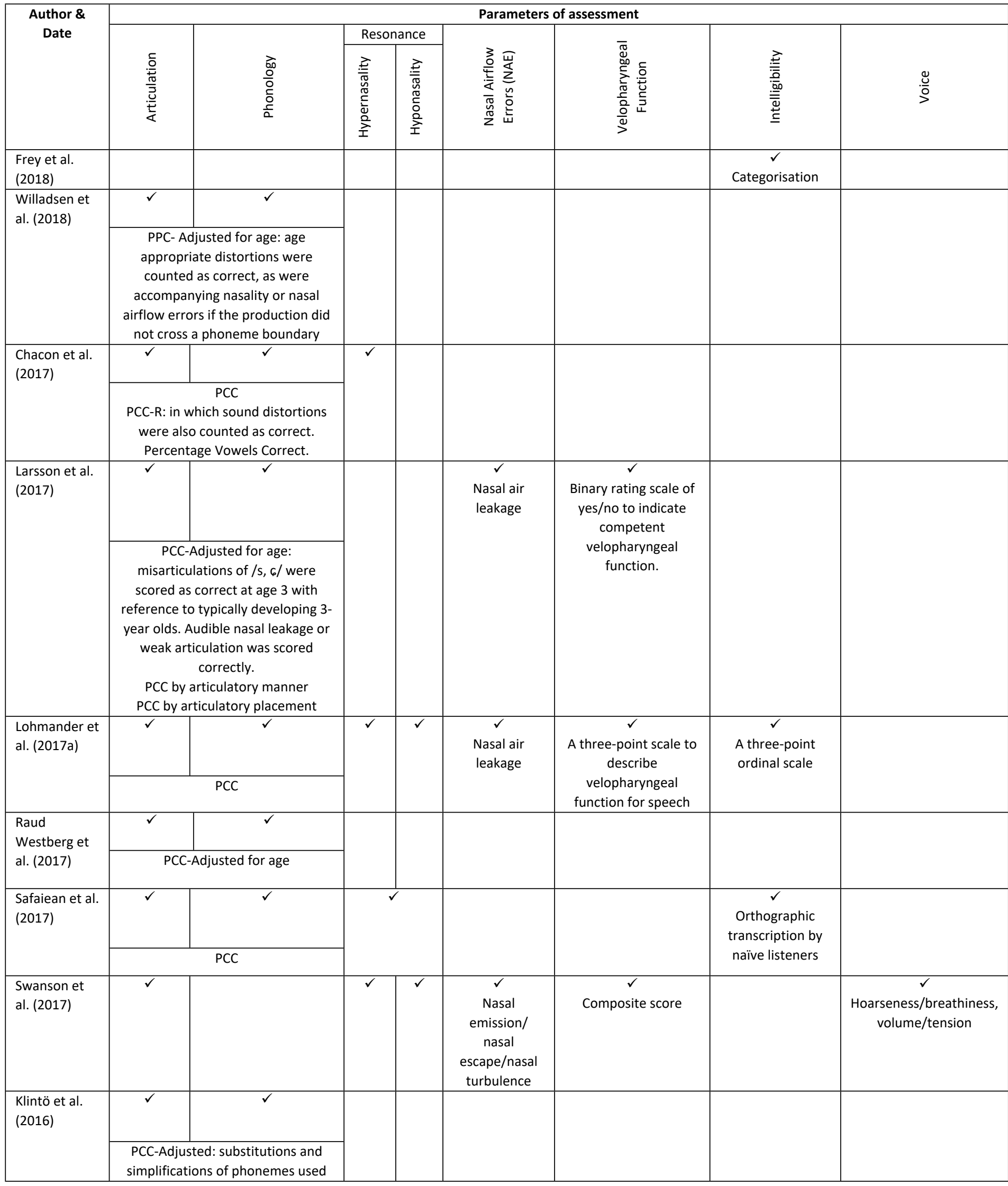




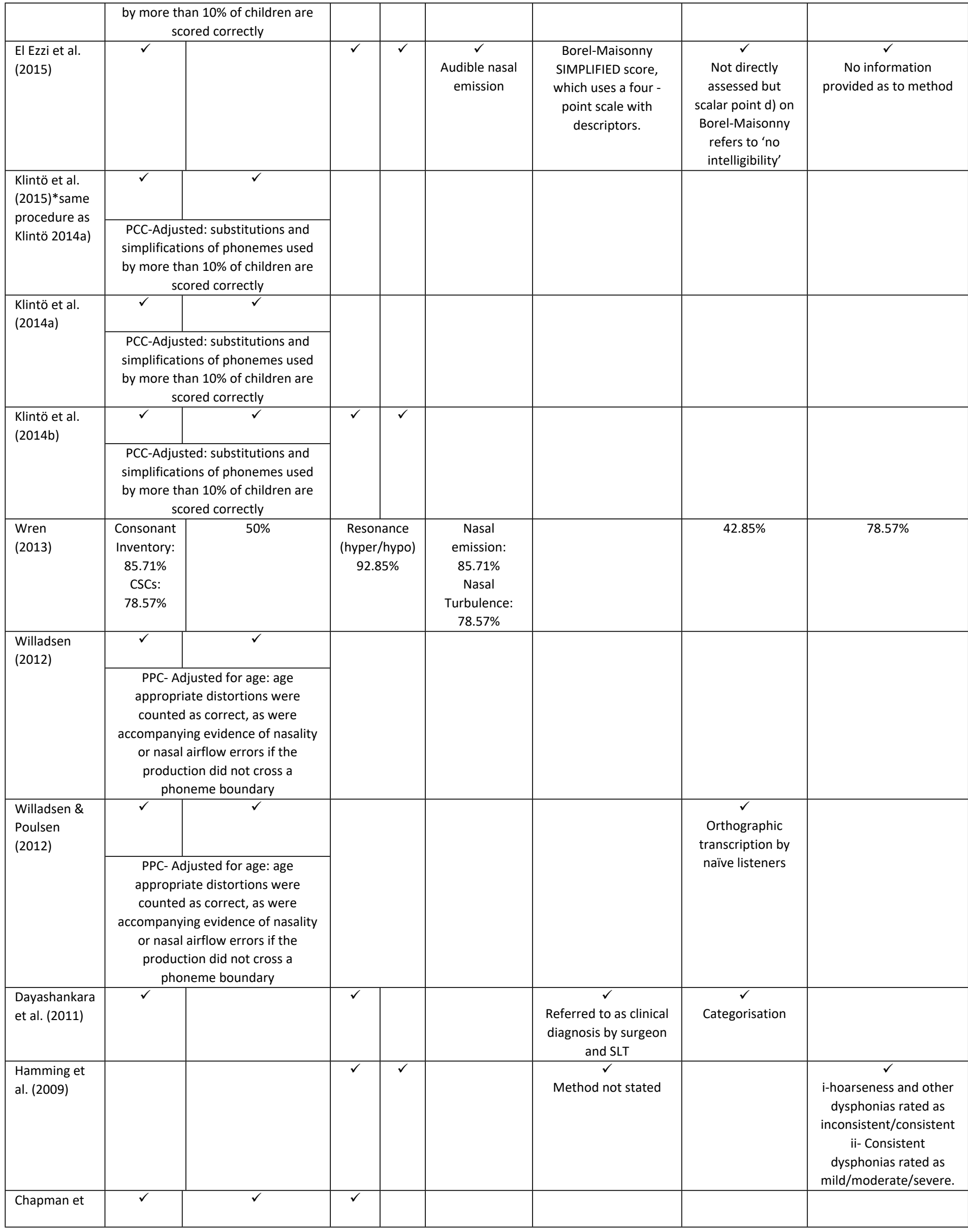




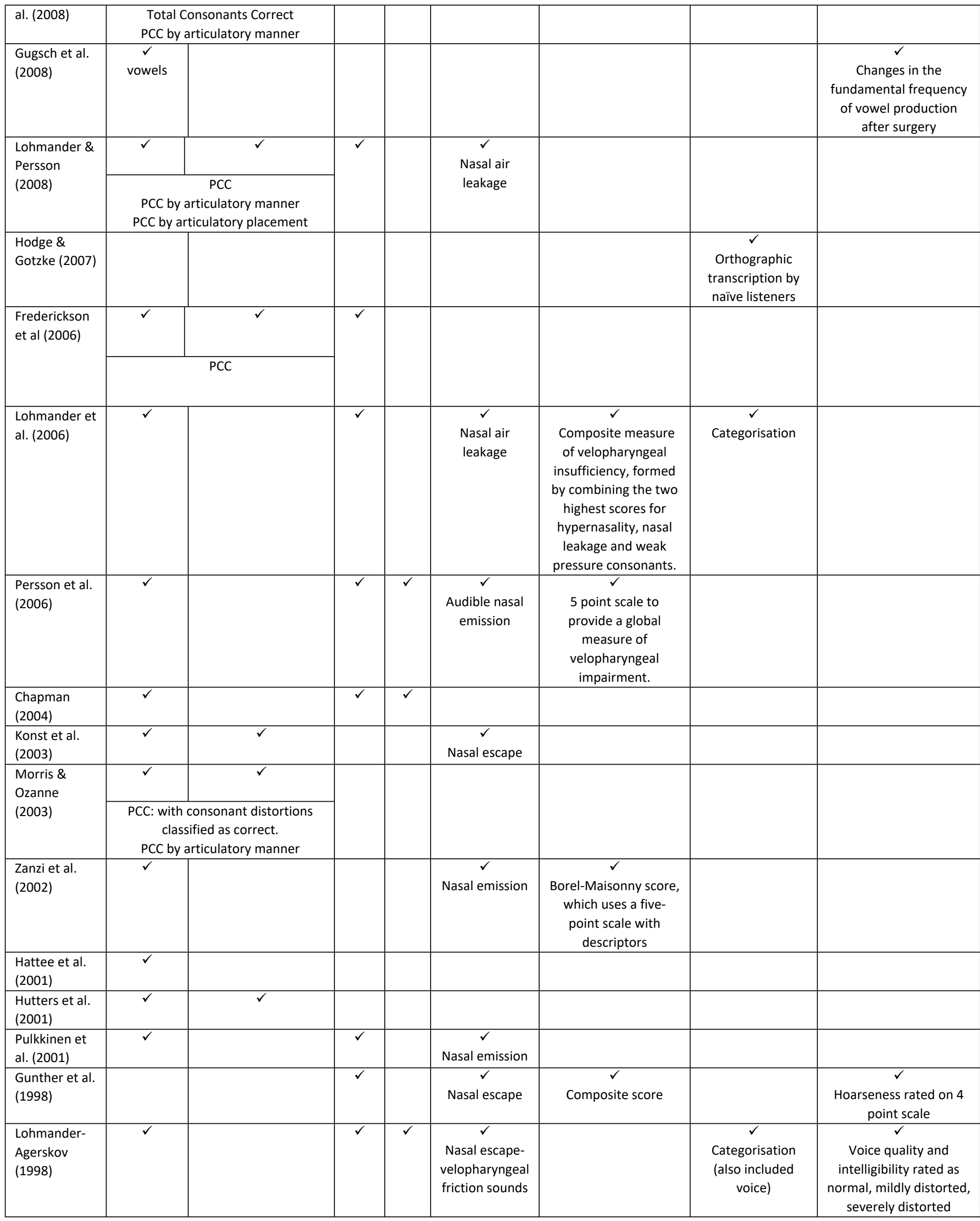




\begin{tabular}{|l|l|l|l|l|l|l|l|l|}
\hline $\begin{array}{l}\text { Lohmander- } \\
\text { Agerskov et } \\
\text { al. (1998) }\end{array}$ & $\checkmark$ & $\checkmark$ & $\checkmark$ & $\begin{array}{c}\checkmark \\
\text { Nasal escape- } \\
\text { velopharyngeal } \\
\text { friction sounds }\end{array}$ & & & $\begin{array}{c}\checkmark \\
\text { Categorisation }\end{array}$ & \\
\hline
\end{tabular}


Figure 1. Adapted PRISMA Extension for Scoping Reviews (PRISMA-ScR) (Tricco et al. 2016)

Figure 1. Adapted PRISMA Extension for Scoping Reviews (PRISMA-ScR) (Tricco et al. 2016) Flow Diagram selection of sources

$437 \times 618 \mathrm{~mm}(72 \times 72 \mathrm{DPI})$ 


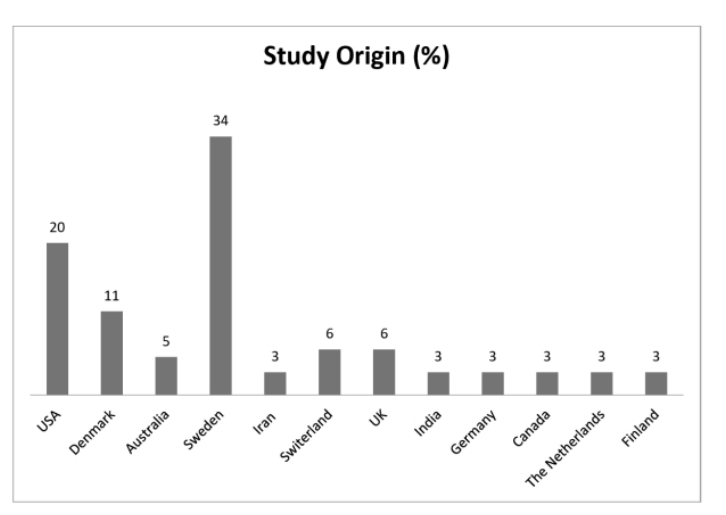

Figure 2. Study Origin

$297 \times 210 \mathrm{~mm}(200 \times 200$ DPI $)$

URL: http:/mc.manuscriptcentral.com/tlcd Email: ijlcdeditorialoffice@city.ac.uk 
Figure 3. Methods used to assess consonant production $210 \times 297 \mathrm{~mm}(200 \times 200 \mathrm{DPI})$ 


\section{References}

ARKSEY, H., \& O'MALLEY, L., 2005, Scoping studies: Towards a methodological framework. International Journal of Social Research Methodology, 8(1), 19-32.

BAYLIS, A., CHAPMAN, K. and WHITEHILL, T.L., 2015, Validity and reliability of visual analogue scaling for assessment of hypernasality and audible nasal emission in children with repaired cleft palate. The Cleft Palate-Craniofacial Journal, 52(6), 660-670.

BRITTON, L., ALBERY, L., BOWDEN, M., HARDING-BELL, A., PHIPPEN, G. and SELL, D., 2014, A cross-sectional cohort study of speech in five-year-olds with cleft palate \pm lip to support development of national audit standards: benchmarking speech standards in the United Kingdom. The Cleft Palate-Craniofacial Journal, 51(4), 431-451.

CAVALHEIRO, M.G., LAMÔNICA, D.A.C., DE VASCONSEllOS HAGE, SIMONE ROCHA and MAXIMINO, L.P., 2019, Child development skills and language in toddlers with cleft lip and palate. International Journal of Pediatric Otorhinolaryngology, 116, 18-21.

CHAPMAN, K.L., BAYLIS, A., TROST-CARDAMONE, J., CORDERO, K.N., DIXON, A., DOBBElSTEYN, C., THURMES, A., WILSON, K., HARDING-BELL, A. and SWEENEY, T., 2016, The Americleft Speech Project: a training and reliability study. The Cleft Palate-Craniofacial Journal, 53(1), 93-108.

CHAPMAN, K.L, and Willadsen, E., 2011, The Development of Speech in Children with Cleft Palate. In S. Howard S., and A. Lohmander (eds), Cleft Palate Speech:

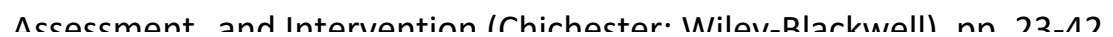
CHAPMAN, K.L., HARDIN-JONES, M. and HALTER, K.A., 2003, The relationship between early speech and later speech and language performance for children with cleft lip and palate. Clinical linguistics \& phonetics, 17(3), 173-197.

CLEFT PALATE INTERNATIONAL SPEECH ISSUES (CLISPI). n.d, Speech material to be collected at different ages. (available at: https://www.clispi.org/en/node/17) [accessed on 11 August 2018]. 
CRANE., 2019, Annual Report on Cleft Lip and/or Palate 2019 [online] https:// crane-database.org.uk/?!.iD=3I [accessed 01 October 2019].

DODD, B., ZHU, H., CROSBIE, S., HOLM, A. and OZANNE, A., 2002, Diagnostic evaluation of articulation and phonology (DEAP). Psychology Corporation.

DOSMAN, C. F., ANDREWS, D., and GOULDEN, K. J., 2012, Evidence-based milestone ages as a framework for developmental surveillance. Paediatrics \& Child Health, 17(10), 561-568.

DUDAS, J. R., DELEYIANNIS, F. W., FORD, M. D., JIANG, S., and LOSEE, J. E., 2006. Diagnosis and treatment of velopharyngeal insufficiency: Clinical utility of speech evaluation and videofluoroscopy. Annals of Plastic Surgery, 56(5), 511-517.

GRUNWELL, P. and SELL, D., 2001, Speech and Cleft Palate/Velopharyngeal Anomalies. In A.C.H Watson., D.A. Sell., P. Grunwell (eds), Management of Cleft Lip and Palate (London: Whurr Publishers), pp. 68-86

HARDING, A. and GRUNWELL, P., 1995. Active versus passive cleft-type speech characteristics: implications for surgery and therapy. International Journal of Language \& Communication Disorders, 30(S1), 242-247.

HENNINGSSON, G., KUEHN, D.P., SELL, D., SWEENEY, T., TROST-CARDAMONE, J.E. and WHITEHILL, T.L., 2008, Universal parameters for reporting speech outcomes in individuals with cleft palate. The Cleft Palate-Craniofacial Journal, 45(1), 1-17.

HOWARD, S., 2011, Phonetic Transcription for Speech Related to Cleft Palate. In S. Howard S., and A. Lohmander (eds), Cleft Palate Speech: Assessment and Intervention (Chichester: Wiley-Blackwell), pp. 127-144.

HUTTERS, B., BAU, A. and BRØNDSTED, K., 2001, A longitudinal group study of development in Danish children born with and without cleft lip and palate. International journal of language \& communication disorders, 36(4), 447-470. 
HUTTERS, B. and BRØNDSTED, K., 1987, Strategies in cleft palate speech--with special reference to Danish. The Cleft palate journal, 24(2), 126-136.

INTERNATIONAL CONSORTIUM FOR HEALTH OUTCOME MEASUREMENT (ICHOM)., 2017, Cleft Lip and Palate Data Collection version 3.0.6. [online] Available: http://www.ichom.org/medicalconditions/cleft-lip-palate/ [accessed 10 June 2018].

JOHN, A., SELL, D., SWEENEY, T., HARDING-BELL, A. and WILLIAMS, A., 2006, The cleft audit protocol for speech-augmented: A validated and reliable measure for auditing cleft speech. The Cleft palate-craniofacial journal, 43(3), 272-288.

KHALIL, H., PETERS, M., GODFREY, C. M., MCINERNEY, P., SOARES, C. B., \& PARKER, D., 2016, An evidence-based approach to scoping reviews. Worldviews on Evidence-Based Nursing, 13(2), 118-123.

KLINTÖ, K., SALAMEH, E., SVENSSON, H. and LOHMANDER, A., 2011, The impact of speech material on speech judgement in children with and without cleft palate. International journal of language \& communication disorders,46(3), 348-360.

LOHMANDER, A., LUNDEBORG, I. and PERSSON, C., 2017a, SVANTE-The Swedish Articulation and Nasality Test-Normative data and a minimum standard set for cross-linguistic comparison. Clinical linguistics \& phonetics, 31(2), 137-154.

LOHMANDER, A., PERSSON, C., WilladSen, E., LUNDEBORG, I., ALALUUSUA, S., AUKNeR, R., BAU, A., BOERS, M., BOWDEN, M. and DAVIES, J., 2017b, Scandcleft randomised trials of primary surgery for unilateral cleft lip and palate: 4 . Speech outcomes in 5-year-olds-velopharyngeal competency and hypernasality. Journal of Plastic Surgery and Hand Surgery, 51(1), 27-37.

LOHMANDER, A., WILLADSEN, E., PERSSON, C., HENNINGSSON, G., BOWDEN, M. and HUTTERS, B., 2009, Methodology for speech assessment in the Scandcleft project-an international 
randomized clinical trial on palatal surgery: experiences from a pilot study. The Cleft PalateCraniofacial Journal, 46(4), 347-362.

LOHMANDER, A., BORELL, E., HENNINGSSON, G., HAVSTAM, C., LUNDEBORG, I. \& PERSSON, C., 2005. SVANTE Svenskt artikulations- och nasalitets-test, Manual [In Swedish]. (Lund: Studentlitteratur).

MCLEOD, S. and BAKER, E., 2017, Children's Speech: An Evidence-Based Approach to Assessment and Intervention (Boston: Pearson)

MCLEOD, S., HARRISON, L.J. and MCCORMACK, J., 2012, The intelligibility in context scale: Validity and reliability of a subjective rating measure. Journal of Speech, Language, and Hearing Research, 55(2), 648-656.

MCWILLIAMS, B. and PHILIPS, B.J., 1979, Velopharyngeal Incompetence audio seminars in speech pathology (Philadelphia: WB Saunders)

MUNN, Z., PETERS, M. D., STERN, C., TUfANARU, C., MCARTHUR, A., \& AROMATARIS, E., 2018, Systematic review or scoping review? guidance for authors when choosing between a systematic or scoping review approach. BMC Medical Research Methodology, 18(1), 143.

PETERS, M.D., GODFREY, C.M., KHALIL, H., MCINERNEY, P., PARKER, D. and SOARES, C.B., 2015, Guidance for conducting systematic scoping reviews. International journal of evidence-based healthcare, 13(3), 141-146.

PEREIRA, V. J., SELL, D., and TUOMAINEN, J., 2013, Effect of maxillary osteotomy on speech in cleft lip and palate: Perceptual outcomes of velopharyngeal function. International Journal of Language \& Communication Disorders, 48(6), 640-650.

PRATHANEE, B., LORWATANAPONGSA, P., ANANTAPONG, D. and BUAKANOK, N., 2011, Thai speech parameters for patients with cleft palate in a universal reporting system. Asia Pacific Journal of Speech, Language and Hearing, 14(1), 31-49. 
SAFAIEAN, A., JALILEVAND, N., EBRAHIMIPOUR, M., ASLESHIRIN, E. and HIRADFAR, M., 2017, Speech intelligibility after repair of cleft lip and palate. Medical Journal of The Islamic Republic of Iran (MJIRI), 31(1), 500-504.

SELL, D., and PEREIRA, V., 2015, Speech: perceptual and functional outcomes. In J. Losee., and RE, Kirschner (eds), Comprehensive Cleft Care. (London: McGraw Hill; editors), pp. 689-714 SELL, D., JOHN, A., HARDING-BELL, A., SWEENEY, T., HEGARTY, F. and FREEMAN, J., 2009, Cleft Audit Protocol for Speech (CAPS-A): a comprehensive training package for speech analysis. International Journal of Language \& Communication Disorders, 44(4), 529-548.

SELL, D., 2005, Issues in perceptual speech analysis in cleft palate and related disorders: a review. International Journal of Language \& Communication Disorders, 40(2), 103-121.

SELL, D. and GRUNWELL, P. 2001, Speech Assessment and Therapy. In A.C.H Watson., D.A. Sell., P. Grunwell (eds), Management of Cleft Lip and Palate (London: Whurr Publishers), pp. $227-257$

SELL, D., HARDING, A. and GRUNWELL, P., 1999, GOS. SP. ASS.'98: an assessment for speech disorders associated with cleft palate and/or velopharyngeal dysfunction (revised). International Journal of Language \& Communication Disorders, 34(1), 17-33.

SHRIBERG, L.D., AUSTIN, D., LEWIS, B.A., MCSWEENY, J.L. and WILSON, D.L., 1997, The percentage of consonants correct (PCC) metric: Extensions and reliability data. Journal of Speech, Language, and Hearing Research, 40(4), 708-722.

SHRIBERG, L.D. and KWIATKOWSKI, J., 1982, Phonological disorders III: A procedure for assessing severity of involvement. Journal of speech and Hearing Disorders, 47(3), 256-270.

SWEENEY, T., 2011, Nasality- Assessment and Intervention. In S. Howard., and A. Lohmander (eds), Cleft Palate Speech: Assessment and Intervention (Chichester: WileyBlackwell), pp. 199-220. 
TILLMAN, K. K., HAKELIUS, M., HÖIJER, J., RAMKLINT, M., EKSELIUS, L., NOWINSKI, D., and PAPADOPOULOS, F. C., 2018, Increased risk for neurodevelopmental disorders in children with orofacial clefts. Journal of the American Academy of Child and Adolescent Psychiatry, 57(11), 876.

TRICCO, A. C., LILLIE, E., ZARIN, W., O'BRIEN, K., COLQUHOUN, H., KASTNER, M., AND WILSON, K., 2016, A scoping review on the conduct and reporting of scoping reviews. BMC Medical Research Methodology, 16(1), 15.

WHITEHILL, T.L., 2002, Assessing intelligibility in speakers with cleft palate: a critical review of the literature. The Cleft palate-craniofacial journal, 39(1), 50-58.

WHITEHILL, T. L., GOTZKE, C. and Hodge, M., 2011, Speech Intelligibility. In S. Howard S., and A. Lohmander (eds), Cleft Palate Speech: Assessment and Intervention (Chichester: WileyBlackwell), pp. 293-304.

WHO., 2007, International Classification of Functioning, Disability and Health. Children and Youth Version [online]

Willadsen, E., LOHMANDer, A., PerSSON, C., LUndeborG, I., AlaluUsuA, S., AUKNeR, R., BAU, A., BOERS, M., BOWDEN, M. and DAVIES, J., 2017, Scandcleft randomised trials of primary surgery for unilateral cleft lip and palate: 5. Speech outcomes in 5-year-olds-consonant proficiency and errors. Journal of plastic surgery and hand surgery, 51(1), 38-51.

WREN, Y., 2013, 'A survey of the assessment procedures at 24 and 36 months in UK Cleft Centres', The Cleft Collective Speech and Language Study. (Unpublished survey).

YAMASHITA, R.P., BORG, E., GRANQVIST, S. and LOHMANDER, A., 2018, Reliability of Hypernasality Rating: Comparison of 3 Different Methods for Perceptual Assessment. The Cleft Palate-Craniofacial Journal, 1-12. 


\begin{abstract}
Appendix 1:
List of articles included in scoping review

CHACON, A., PARKIN, M., BROOME, K. and PURCELL, A., 2017, Australian

children with cleft palate achieve age-appropriate speech by 5 years-of-

age. International Journal of Pediatric Otorhinolaryngology, 103, 93-102.
\end{abstract}

CHAPMAN, K.L., HARDIN-JONES, M.A., GOLDSTEIN, J.A., HALTER, K.A., HAVLIK, R.J. and SCHULTE, J., 2008, Timing of palatal surgery and speech outcome. The Cleft Palate-Craniofacial Journal, 45(3), 297-308.

CHAPMAN, K.L., 2004, Is presurgery and early postsurgery performance related to speech and language outcomes at 3 years of age for children with cleft palate? Clinical Linguistics \& Phonetics, 18(4-5), 235-257.

DAYASHANKARA, R.J., SINGH, S., SUMA, G.N., GOKKULA, K., KUMAR, V. and SURSH, B.S., 2011, Comparative study of 2 palatoplasty techniques to assess speech and fistula in primary cleft palate patients. Journal of Dentistry for Children, 78(1), 13-18.

EL EZZI, O., HERZOG, G., BROOME, M., TRICHET-ZBINDEN, C., HOHLFELD, J., CHERPILLOD, J. and DE BUYS ROESSINGH, ANTHONY S., 2015, Grommets and speech at three and six years in children born with total cleft or cleft palate. International Journal of Pediatric Otorhinolaryngology, 79(12), 2243-2247. 
FREDERICKSON, M.S., CHAPMAN, K.L. and HARDIN-JONES, M., 2006, Conversational skills of children with cleft lip and palate: a replication and extension. The Cleft Palate-Craniofacial Journal, 43(2), 179-188.

FREY, J.R., KAISER, A.P. and SCHERER, N.J., 2018, The influences of child intelligibility and rate on caregiver responses to toddlers with and without cleft palate. The Cleft Palate-Craniofacial Journal, 276-286.

GUNTHER, E., WISSER, J.R., COHEN, M.A. and BROWN, A.S., 1998, Palatoplasty: Furlow's double reversing Z-plasty versus intravelar veloplasty. The Cleft Palate-Craniofacial Journal, 35(6), 546-549.

GUGSCH, C., DANNHAUER, K. and FUCHS, M., 2008, Evaluation of the progress of therapy in patients with cleft lip, jaw and palate, using voice analysis- a pilot study. Journal of Orofacial Orthopedics, 69(4), 257-267.

HAMMING, K.K., FINKELSTEIN, M. and SIDMAN, J.D., 2009, Hoarseness in children with cleft palate. Otolaryngology—Head and Neck Surgery, 140(6), 902-906.

HATTEE, C., FARROW, K., HARLAND, K., SOMMERLAD, B. and WALSH, M., 2001, Are we ready to predict speech development from babble in cleft lip and palate children? International Journal of Language \& Communication Disorders, 36(S1), 115-120. 
HODGE, M. and GOTZKE, C.L., 2007, Preliminary results of an intelligibility measure for English-speaking children with cleft palate. The Cleft Palate-Craniofacial Journal, 44(2), 163-174.

HUTTERS, B., BAU, A. and BRØNDSTED, K., 2001, A longitudinal group study of speech development in Danish children born with and without cleft lip and palate. International Journal of Language \& Communication Disorders, 36(4), 447-470.

KLINTÖ, K., SALAMEH, E. and LOHMANDER, A., 2016, Phonology in Swedishspeaking 5-year-olds born with unilateral cleft lip and palate and the relationship with consonant production at 3 years of age. International Journal of Speech-Language Pathology, 18(2), 147-156.

KLINTÖ, K., SALAMEH, E. and LOHMANDER, A., 2015, Verbal competence in narrative retelling in 5 year olds with unilateral cleft lip and palate. International Journal of Language \& Communication Disorders, 50(1), 119-128.

KLINTÖ, K., OLSSON, M., FLYNN, T., SVENSSON, H. and LOHMANDER, A., 2014a, Phonology in Swedish-speaking 3-year-olds born with cleft lip and palate and the relationship with consonant production at 18 months. International Journal of Language \& Communication Disorders, 49(2), 240-254.

KLINTÖ, K., SVENSSON, H., ELANDER, A. and LOHMANDER, A., 2014b, Speech and phonology in Swedish-speaking 3-year-olds with unilateral complete cleft lip and 
palate following different methods for primary palatal surgery. The Cleft PalateCraniofacial Journal, 51(3), 274-282.

KONST, E.M., RIETVELD, T., PETERS, H.F. and PRAHL-ANDERSEN, B., 2003, Phonological development of toddlers with unilateral cleft lip and palate who were treated with and without infant orthopedics: a randomized clinical trial. The Cleft Palate-Craniofacial Journal, 40(1), 32-39.

LARSSON, A., SCHÖLIN, J., MARK, H., JÖNSSON, R. and PERSSON, C., 2017, Speech production in 3 year old internationally adopted children with unilateral cleft lip and palate. International Journal of Language \& Communication Disorders, 52(5), 626-636.

LOHMANDER-AGERSKOV, A., 1998, Speech outcome after cleft palate surgery with the Gothenburg regimen including delayed hard palate closure. Scandinavian Journal of Plastic and Reconstructive Surgery and Hand Surgery, 32(1), 63-80.

LOHMANDER-AGERSKOV, A., SÖDERPALM, E., FRIEDE, H. and LILJA, J., 1998, A comparison of babbling and speech at pre-speech level, 3, and 5 years of age in children with cleft lip and palate treated with delayed hard palate closure. Folia Phoniatrica et Logopaedica, 50(6), 320-334.

LOHMANDER, A. and PERSSON, C., 2008, A longitudinal study of speech production in Swedish children with unilateral cleft lip and palate and two-stage palatal repair. The Cleft Palate-Craniofacial Journal, 45(1), 32-41. 
LOHMANDER, A., LUNDEBORG, I. and PERSSON, C., 2017a, SVANTE-The

Swedish Articulation and Nasality Test-Normative data and a minimum standard set for cross-linguistic comparison. Clinical linguistics \& phonetics, 31(2), 137-154.

LOHMANDER, A., FRIEDE, H., ELANDER, A., PERSSON, C. and LILJA, J., 2006, Speech development in patients with unilateral cleft lip and palate treated with different delays in closure of the hard palate after early velar repair: a longitudinal perspective. Scandinavian Journal of Plastic and Reconstructive Surgery and Hand Surgery, 40(5), 267-274.

MORRIS, H. and OZANNE, A., 2003, Phonetic, phonological, and language skills of children with a cleft palate. The Cleft Palate-Craniofacial Journal, 40(5), 460-470.

PERSSON, C., LOHMANDER, A. and ELANDER, A., 2006, Speech in children with an isolated cleft palate: a longitudinal perspective. The Cleft Palate-Craniofacial Journal, 43(3), 295-309.

PULKKINEN, J., HAAPANEN, M., PAASO, M., LAITINEN, J. and RANTA, R., 2001, Velopharyngeal function from the age of three to eight years in cleft palate patients. Folia Phoniatrica et Logopaedica, 53(2), 93-98.

RAUD WESTBERG, L., HÖGLUND SANTAMARTA, L., KARLSSON, J., NYBERG, J., NEOVIUS, E. and LOHMANDER, A., 2017, Speech outcome in young children born with unilateral cleft lip and palate treated with one-or two-stage palatal repair 
and the impact of early intervention. Logopedics Phoniatrics Vocology, DOI: $10.1080 / 14015439.2017 .1390606$

SAFAIEAN, A., JALILEVAND, N., EBRAHIMIPOUR, M., ASLESHIRIN, E. and HIRADFAR, M., 2017, Speech intelligibility after repair of cleft lip and palate. Medical Journal of The Islamic Republic of Iran (MJIRI), 31(1), 500-504.

SWANSON, J.W., MITCHELL, B.T., COHEN, M., SOLOT, C., JACKSON, O., LOW, D., BARTLETT, S.P. and TAYLOR, J.A., 2017, The effect of Furlow palatoplasty timing on speech outcomes in submucous cleft palate. Annals of Plastic Surgery, 79(2), 156-161.

WILLADSEN, E., BOERS, M., SCHÖPS, A., KISLINGMØLLER, M., NIELSEN, J.B., JØRGENSEN, L.D., ANDERSEN, M., BOLUND, S. and ANDERSEN, H.S., 2018, Influence of timing of delayed hard palate closure on articulation skills in 3year-old Danish children with unilateral cleft lip and palate. International Journal of Language \& Communication Disorders, 53(1), 130-143.

WILLADSEN, E., 2012, Influence of timing of hard palate repair in a two-stage procedure on early speech development in Danish children with cleft palate. The Cleft Palate-Craniofacial Journal, 49(5), 574-595.

WILLADSEN, E. and POULSEN, M., 2012, A restricted test of single-word intelligibility in 3-year-old children with and without cleft palate. The Cleft PalateCraniofacial Journal, 49(3), 6-16. 
WREN, Y., 2013, A survey of the assessment procedures at 24 and 36 months in UK cleft centres, The Cleft Collective Speech and Language Study. (Unpublished survey).

ZANZI, M., CHERPILLOD, J. and HOHLFELD, J., 2002, Phonetic and ontological results after early palate closure in 18 consecutive children presenting with cleft lip and palate. International Journal of Pediatric Otorhinolaryngology, 66(2), 131-137. 
Dear Dr McKean,

We would like to thank you and the reviewers for your thoughtful and detailed feedback on our submission. We have considered all of the feedback as detailed below and this has served to improve the quality of the manuscript.

In particular, the main focus of the changes has been to strengthen the rationale for the scoping review methodology and a significant re-write of the Discussion section to address theoretical approaches to assessment and relevance to clinical practice and future research.

Major changes to the original manuscript have been highlighted, and a detailed description of the changes is reported below.

\begin{tabular}{|c|c|c|}
\hline Editor Comment & Response & Location \\
\hline $\begin{array}{l}\text { Why you have chosen to do a } \\
\text { scoping review rather than a } \\
\text { systematic review }\end{array}$ & $\begin{array}{l}\text { The rationale for a scoping rather than systematic } \\
\text { review has been strengthened in the manuscript. The } \\
\text { aim of the review is to broadly map assessment } \\
\text { practices, rather than focus on quality appraisal or } \\
\text { effectiveness. This aim is to use this information to } \\
\text { inform the design of a UK Assessment Protocol at age } \\
\text { 3-years. The expansive inclusion criteria of a scoping } \\
\text { review was also appropriate given the aim to provide } \\
\text { a comprehensive overview of assessment practices. } \\
\text { Had the scope of the review been limited to articles } \\
\text { from a particular country, or type of assessment, not } \\
\text { only would the usability of the review have been } \\
\text { limited but potentially valuable information could } \\
\text { have been missed. In addition, the aims of the review } \\
\text { were not to aggregate findings but to address key } \\
\text { issues through the charting of data which is in keeping } \\
\text { with a scoping review methodology. Additional } \\
\text { references have been introduced to support these } \\
\text { justifications: Arksey, H., \& O'Malley, L. (2005), Khalil } \\
\text { et al. (2016), Munn et al. (2018), Peters et al. (2015) } \\
\text { and Tricco et al. (2018). } \\
\text { The lack of clarity between a scoping and systematic } \\
\text { review methodology has been clarified by omitting } \\
\text { comments on reliability, which is better suited to a } \\
\text { systematic review and was not fully in line with the } \\
\text { aims of this review. The aims of the scoping review } \\
\text { have been more clearly stated. } \\
\text { Of relevance is the following paragraph: } \\
\text { "In order to examine the methods, parameters of } \\
\text { assessment (whether developmental or cleft specific) } \\
\text { and speech samples utilised in the assessment of } \\
\text { speech in children with CP } \pm \text { L at age 3-years, a broad } \\
\text { scope of enquiry was required. This was achieved } \\
\text { through the use of a scoping review methodology } \\
\text { (Khalil et al. 2016). This methodology was preferred } \\
\text { given that the intention behind the work was to }\end{array}$ & $\begin{array}{l}\text { Abstract } \\
\text { Line 12-13 } \\
\text { What this paper } \\
\text { adds } \\
\text { Line 5-6 } \\
\text { Main text } \\
\text { Introduction } \\
\text { Page } 3 \text { Line 9-22 } \\
\text { Methods } \\
\text { Page 4 Line 10-11 }\end{array}$ \\
\hline
\end{tabular}




\begin{tabular}{|c|c|c|}
\hline & $\begin{array}{l}\text { inform the future development of assessment } \\
\text { procedures at age 3-years in the UK. Rather than } \\
\text { answer an effectiveness question (Peters et al. 2015), } \\
\text { evaluate study quality, or limit the review to a } \\
\text { particular study design (Arksey and O'Malley 2005) or } \\
\text { country of origin, the scoping review methodology } \\
\text { was used to broadly map current practices, in order } \\
\text { to clarify the key concepts, identify gaps in the } \\
\text { evidence base and make recommendations for future } \\
\text { practice in the UK. In doing so the review will identify } \\
\text { the extent to which there is consensus in the } \\
\text { parameters of assessment, procedures and methods; } \\
\text { differences and similarities in assessment at age } 3 \\
\text { years compared to practice at age 5; the types of } \\
\text { speech samples used (Munn et al. 2018)." }\end{array}$ & \\
\hline $\begin{array}{l}\text { Make clearer what this paper } \\
\text { adds over and above simply } \\
\text { providing a descriptive list of } \\
\text { assessment approaches }\end{array}$ & $\begin{array}{l}\text { The importance of a developmental approach to } \\
\text { assessment at age } 3 \text { in the } C P \pm L \text { has been highlighted } \\
\text { throughout the manuscript. This brings to the fore } \\
\text { reasons why assessments at age } 3 \text { and those } \\
\text { established for other age groups are different. This is } \\
\text { particularly relevant in the CP } \pm \text { population given that } \\
\text { the focus of assessment at older age groups is often } \\
\text { on cleft specific outcomes. In addition, the review } \\
\text { highlights the need for multiple approaches to } \\
\text { assessment to assess speech at this age. } \\
\text { In the discussion and conclusion sections a greater } \\
\text { emphasis has been placed on highlighting those areas } \\
\text { in which assessment practices differ at age } 3 \text { in } \\
\text { comparison to older age groups i.e. the type of } \\
\text { speech sample used, the use of a developmental } \\
\text { approach to assessment and the potential for the use } \\
\text { of an overall measure of VP function. } \\
\text { Finally, through a broad appraisal of the literature, } \\
\text { the lack of consensus regarding speech samples and } \\
\text { methods of assessment is revealed. This highlights } \\
\text { potential research opportunities. }\end{array}$ & 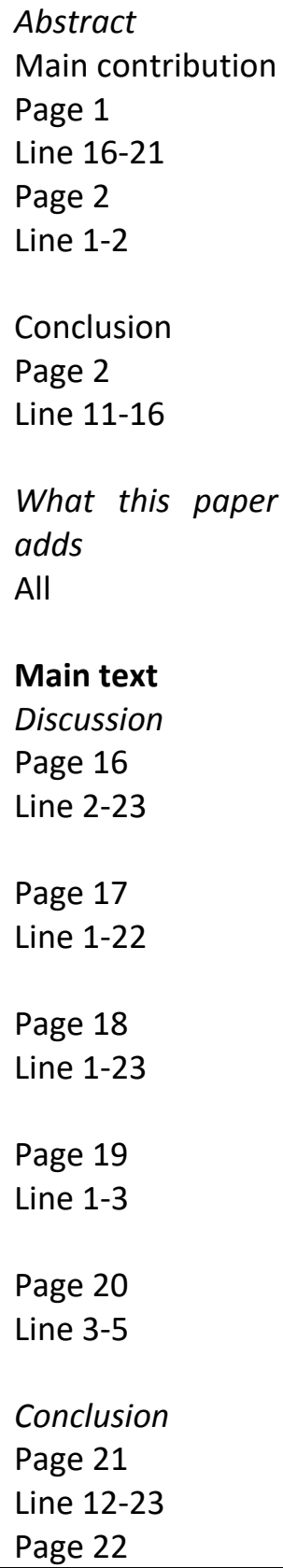 \\
\hline
\end{tabular}




\begin{tabular}{|c|c|c|}
\hline & & \begin{tabular}{|l} 
Line $1-4$ \\
\end{tabular} \\
\hline $\begin{array}{l}\text { Theoretical motivations } \\
\text { which might make } \\
\text { researchers/clinicians choose } \\
\text { some over others }\end{array}$ & $\begin{array}{l}\text { The discussion section of the manuscript has been } \\
\text { extensively re-written to highlight the different } \\
\text { theoretical approaches to assessment, reasons as to } \\
\text { why they have been used, and the need to use } \\
\text { different theoretical approaches in conjunction to } \\
\text { assess speech at age } 3 \text { years in this population. This } \\
\text { includes the discussion of a medical model, linguistic, } \\
\text { developmental and functional approaches to } \\
\text { assessment. }\end{array}$ & $\begin{array}{l}\text { Main text } \\
\text { Discussion } \\
\text { All }\end{array}$ \\
\hline $\begin{array}{l}\text { What you would recommend } \\
\text { both for clinical practice and } \\
\text { future research }\end{array}$ & $\begin{array}{l}\text { Clinical Practice: } \\
\text { The need for multiple theoretical approaches for } \\
\text { assessment, used in combination to assess speech at } \\
\text { age 3-years is highlighted. In particular, the need to } \\
\text { take a developmental and functional perspective is } \\
\text { discussed through the examination of the assessment } \\
\text { methods and parameters of assessment. Key } \\
\text { differences between assessments at older ages and } \\
\text { age } 3 \text { are described. }\end{array}$ & $\begin{array}{l}\text { Abstract } \\
\text { Page 1 } \\
\text { Line 16-21 } \\
\text { Page 2 } \\
\text { Line 1-2 } \\
\text { Line 11-13 } \\
\text { What this paper } \\
\text { adds } \\
\text { Line 8-9 } \\
\text { Main text } \\
\text { Discussion } \\
\text { Page 17 } \\
\text { Line 11-23 } \\
\text { Page 18 } \\
\text { Line 1-23 } \\
\text { Page 19 } \\
\text { Line 1-3 } \\
\text { Page 20 } \\
\text { Line 3-5 } \\
\text { Conclusion } \\
\text { Page 21 } \\
\text { Line 15-20 } \\
\text { Abstract } \\
\text { Page 2 } \\
\text { Line 15-16 } \\
\text { What this paper } \\
\text { adds } \\
\text { Line 16-19 } \\
\text { Main text } \\
\text { Discussion } \\
\text { Page 16 } \\
\text { Line 13-16 } \\
\text { Line 21-23 }\end{array}$ \\
\hline
\end{tabular}


Page 17

Line 1-6 speech samples in terms of completion rates and listener reliability is discussed. This is particularly relevant as age 3-years may not be able to produce the same complex samples used to assess outcomes in older age groups. The relationship between speech samples and reliability has not be investigated at age 3 the same way it has at age 5 (Klintö et al. 2011).

- The potential for the use of the Restricted Word List to allow for cross-linguistic comparisons is discussed. However, the further development of the word list is required in order to complete a comprehensive assessment of disordered speech.

\section{Reviewer 1 Comment} Are the authors able to mention what motivated them to conduct a scoping review over other types of reviews (e.g. systematic review)?

\section{Response}

Thank you for highlighting this point. We appreciate that we have not been sufficiently clear as to why a scoping review was selected as opposed to a systematic review. The justification and rationale for the scoping review has been clarified in the amended manuscript. The aim to review assessment practices at age 3 -years is broad. The motivation of the review being not to aggregate findings or appraise quality but to understand the breadth and scope of assessment practices, in order to identify key concepts and core elements central to assessment at this age (which may or may not differ to assessments at older age groups) in order to identify gaps in the research, and if possible make recommendations regarding assessments protocols in the UK. With this in mind the methodology best suited to meet these objectives is a scoping rather than systematic review. Additional references have been included to support the rationale for using a scoping review methodology: Arksey, H., \& O'Malley, L. (2005), Khalil et al. (2016), Munn et al. (2018), Peters et al. (2015) and Tricco et al. (2018).

The potential for confusion as to the methodology may relate to the inclusion or reliability measures. As such comments about reliability have been edited from the manuscript as this potentially clouded the justification between scoping and systematic reviews. (2018) who produced the PRISMA Extension for
Page 18

Line 22-23

Page 19

Line 1-3

Conclusion

Page 21

Line 21-23

Page 22

Line 1-4

\section{Location}

Abstract

Line $12-13$

What this paper adds

Line 5-6

Main text

Introduction

Page 3 Line 9-22

Methods

Page 4 Line 10-11

Figure 1 
I wish the authors could have performed a quality appraisal of the studies that were included.

I wonder why the authors did not compare the reliability of the assessment practices from all the included studies.
Scoping Reviews. The flowchart is in line with the illustration used in this paper, and this reference is a better fit with the paper given the use of a scoping review.

The justification for not limiting the study to a single country has been explained in the amended manuscript.

This now reads:

"To broaden the examination, no preference was given to literature from any specific country" languages were spoken. In this way, the authors could have made equitable comparisons across studies and identified reliable assessment practices.

An expansive inclusion criterion is in keeping with a scoping review methodology. A result of narrowing the review to certain countries i.e. to the UK only, would be to miss useful practices in other countries e.g. the use of a cross-linguistic assessment. Indeed, this review highlights the potential of cross-linguistic speech samples, to facilitate the comparison of outcomes between countries which would be lost if the remit of the review was narrowed. Indeed, given the rarity of $\mathrm{CP} \pm \mathrm{L}$ (approx. 1 in 1000 births) there is a need to learn from research in other countries. Historically, the sharing of practices internationally has brought about significant changes to cleft care (e.g. the CSAG review in the UK in response to the Shaw et al. [1992] international study of cleft outcomes).

A further justification for not limiting the review to a single country is that the papers only originated from 12 countries, with some countries only contributing a single paper. Selecting a single country would have significantly narrowed the breadth of the review. Whilst differences are explored, the inclusion of different countries also highlights similarities, indicating core parameters and methods of assessment which require further examination.

The amended manuscript clarifies why a scoping review rather than systematic review was selected. The Joanna Briggs Institute methodology was closely adhered to ensure the methodological rigour of the scoping review. However, a key difference between scoping and systematic reviews is quality appraisal and it was not the aim of this study to appraise the quality of the papers, but to broadly map assessment practices.

In the original manuscript, some of the confusion between scoping and systematic reviews may have been related to the reporting of reliability in the studies.
Main text Methods Page 5, Line 18-19

Main text Introduction Page 3 Line 9-22

\section{Table 3}

Recording of reliability has been removed 


\begin{tabular}{|c|c|c|}
\hline & $\begin{array}{l}\text { The reporting of reliability does not fit well within the } \\
\text { scoping review methodology nor the aims of this } \\
\text { study. In light of this, and for clarity the reporting of } \\
\text { reliability has been omitted in the amended } \\
\text { manuscript. }\end{array}$ & \\
\hline $\begin{array}{l}\text { Finally, the authors should } \\
\text { present their findings in a } \\
\text { manner that would be } \\
\text { applicable for clinical } \\
\text { practice. This would ideally } \\
\text { involve identifying } \\
\text { assessment practices, speech } \\
\text { samples, etc. that are more } \\
\text { reliable over others and } \\
\text { identifying speech samples } \\
\text { that can be used for the } 3- \\
\text { year olds from a } \\
\text { developmental perspective } \\
\text { of the speech and language } \\
\text { skills. }\end{array}$ & $\begin{array}{l}\text { Although reliability was not specifically examined the } \\
\text { amended manuscript more specifically addresses the } \\
\text { following implications for clinical practice: } \\
\text { e.g. } \\
\text { - The need for multiple theoretical approaches } \\
\text { for assessment, used in combination to } \\
\text { comprehensively assess speech. In particular, } \\
\text { the need to use a developmental and } \\
\text { functional perspective is highlighted through } \\
\text { the examination of the assessment methods } \\
\text { and parameters of assessment. } \\
\text { The potential of cross-linguistic assessments } \\
\text { is discussed. } \\
\text { The potential use of an overall measure of } \\
\text { velopharyngeal function is highlighted. } \\
\text { However, key issues such as the lack of consensus as } \\
\text { to the type of speech sample, and the limited use of } \\
\text { sales other than ordinal, highlight the need for further } \\
\text { research. }\end{array}$ & $\begin{array}{l}\text { Abstract } \\
\text { Page 1 } \\
\text { Line 16-21 } \\
\text { Page 2 } \\
\text { Line 1-2 } \\
\text { Line 11-13 } \\
\text { What this paper } \\
\text { adds } \\
\text { Line 8-9 } \\
\text { Main text } \\
\text { Discussion } \\
\text { Page 17 } \\
\text { Line 11-23 } \\
\text { Page 18 } \\
\text { Line 1-23 } \\
\text { Page 19 } \\
\text { Line 1-3 } \\
\text { Page 20 } \\
\text { Line 3-5 } \\
\text { Line 15-20 }\end{array}$ \\
\hline $\begin{array}{l}\text { The findings do not seem to } \\
\text { benefit a practising clinician } \\
\text { or a researcher }\end{array}$ & $\begin{array}{l}\text { As above the amended manuscript specifically } \\
\text { addresses implications for clinical practice and } \\
\text { research. } \\
\text { In addition, the need for further research and the } \\
\text { potential areas of this research are also highlighted } \\
\text { through the broad examination of the literature } \\
\text { through a scoping review. } \\
\text { Specific recommendations for researchers are: } \\
\text { - The need for validation of the ICS at age } 3 \\
\text { years is discussed. } \\
\text { The limited use of "ratio or category-ratio } \\
\text { scales, despite evidence to suggest this is a } \\
\text { more valid measurement of resonance and } \\
\text { NAE requires further investigation. Evidence } \\
\text { has suggested that these types of scales can } \\
\text { be reliably used with older age groups, }\end{array}$ & $\begin{array}{l}\text { Abstract } \\
\text { Line 15-16 } \\
\text { What this paper } \\
\text { adds } \\
\text { Line 16-19 } \\
\text { Main text } \\
\text { Discussion } \\
\text { Page } 16 \\
\text { Line } 13-16 \\
\text { Line } 21-23 \\
\text { Page } 17 \\
\text { Line 1-6 } \\
\text { Page } 18 \\
\text { Line } 22-23\end{array}$ \\
\hline
\end{tabular}




\begin{tabular}{|c|c|c|}
\hline & $\begin{array}{l}\text { however 3year olds have not been } \\
\text { specifically investigated (Yamashita et al. } \\
\text { 2018, Baylis et al. 2015). } \\
\text { - } \\
\text { The need to research the impact of different } \\
\text { speech samples in terms of completion rates } \\
\text { and listener reliability is discussed. This is } \\
\text { particularly relevant as age 3-years may not } \\
\text { be able to produce the same complex } \\
\text { samples used to assess outcomes in older age } \\
\text { groups. The relationship between speech } \\
\text { samples and reliability has not been } \\
\text { investigated at age } 3 \text { the same way it has at } \\
\text { age } 5 \text { (Klintö et al. 2011). } \\
\text { The potential for the use of the Restricted } \\
\text { Word List to allow for cross-linguistic } \\
\text { comparisons is discussed. However, the } \\
\text { further development of the word list is } \\
\text { required in order to complete a } \\
\text { comprehensive assessment of disordered } \\
\text { speech. }\end{array}$ & $\begin{array}{l}\text { Page } 19 \\
\text { Line 1-3 } \\
\text { Conclusion } \\
\text { Page } 21 \\
\text { Line 21-23 } \\
\text { Page 22 } \\
\text { Line 1-4 }\end{array}$ \\
\hline Reviewer 2 Comment & Response & Location \\
\hline $\begin{array}{l}\text { How was grey literature } \\
\text { identified? }\end{array}$ & $\begin{array}{l}\text { The Cleft Care UK Speech and Language Study is an } \\
\text { ongoing longitudinal UK multi-centre study that is } \\
\text { taking place in the cleft centre of the primary author. } \\
\text { Information regarding the study is shared on an } \\
\text { annual basis at the Craniofacial Society of Great } \\
\text { Britain and Ireland's annual scientific conference. } \\
\text { Given that the study is collecting data on speech } \\
\text { outcomes at age 3-years, the primary author directly } \\
\text { contacted the study team to identify if there was any } \\
\text { relevant information connected to the study which } \\
\text { could be considered for the review. This yielded the } \\
\text { unpublished, yet highly relevant survey of assessment } \\
\text { practices in the UK (Wren 2013). Indeed, the inclusion } \\
\text { of this survey in the review may prevent the } \\
\text { replication of this work by other researchers. }\end{array}$ & $\begin{array}{l}\text { Main text } \\
\text { Method } \\
\text { Page } 7 \\
\text { Line 6-12 }\end{array}$ \\
\hline $\begin{array}{l}\text { Please explain what you } \\
\text { mean by 'anatomical } \\
\text { changes' }\end{array}$ & $\begin{array}{l}\text { This has been clarified and now reads: } \\
\text { "anatomical changes (e.g. adenoid atrophy, dentition } \\
\text { and occlusion)" }\end{array}$ & $\begin{array}{l}\text { Main text } \\
\text { Introduction } \\
\text { Page } 1 \\
\text { Line } 12-13\end{array}$ \\
\hline $\begin{array}{l}\text { However, for younger } \\
\text { children, a focus of } \\
\text { assessment may be to } \\
\text { examine the impact of the } \\
\text { cleft on the process of } \\
\text { normal speech development } \\
\text { (articulation and phonology). } \\
\text { This sentence seems to } \\
\text { represent a very narrow view } \\
\text { of speech development - }\end{array}$ & $\begin{array}{l}\text { This has been changed and now reads: } \\
\text { "the process of normal speech sound development" }\end{array}$ & $\begin{array}{l}\text { Main text } \\
\text { Introduction } \\
\text { Page } 1 \\
\text { Line } 15\end{array}$ \\
\hline
\end{tabular}


I suggest revise the very last part of the sentence to 'PCC $<\mathrm{u}>$ and $</ \mathrm{u}>$ summary patterns',

P.20. Lines 48-51: While the category summary issue is true, PCC measures in crosslinguistic /cross-centre studies allow comparison of the overall articulation competence
Clarification has been provided as to the inclusion criteria which applies to all the studies reviewed.

This now reads:

"Literature and sources had to address the following concepts: speech assessments, the types of speech samples and speech parameters assessed, including methods of assessment. This allowed for the inclusion of sources which investigated assessment processes as well as those reporting on speech outcomes."

A definition has been provided. This now reads:

"Relevant Medical Subject Headings (MeSH [vocabulary used to index publications]) were utilised in the database search."

This has been changed to consonant/phoneme inventory to reflect the different definitions used.

Different examples of definitions of consonant/phoneme inventory used in the studies has been provided:

"The criteria for inclusion in the inventory varied across the studies. For example (Hattee et al. 2001) rated the presence of consonants, Morris \& Ozanne (2003) required phonemes to be heard twice to be included, and Lohmander et al. (2017a) reported correct productions in more than $50 \%$ of the targets." This has been reworded to improve clarity and now reads:

"The methods used in the studies to assess consonant production demonstrate that both PCC and summary patterns can provide information about articulation and phonology."

This paragraph has been extensively re-written to reflect the pros and cons of both PCC-A and summary measures particularly in a cross-linguistic context.

This section is particularly relevant:

"Again, challenges in comparing speech outcomes across the studies arise from the use of different criteria and summary patterns (Sell 2005) and the need for consensus is relevant both at age 3 -years and for other age groups. PCC-A, using a controlled speech sample allows for cross-linguistic comparisons and takes into consideration sound distortions
Main text Methods

Page 5

Line 13-16

\section{Main text}

Methods

Page 6

Line 12

Main text

Results

Page 11

Line 1-5

\section{Main text}

Results

Page 11

Line 15-18

\section{Main text}

Discussion

Page 17

Line 11-17 

particularly appropriate for assessment at age 3years. PCC-A may, therefore, offer a partial solution although it has the disadvantage of not capturing the qualitative nature of speech errors." 